\title{
The reductive decyanation reaction: an overview and recent developments
}

\author{
Jean-Marc R. Mattalia
}

\author{
Review \\ Address: \\ Aix-Marseille Univ, CNRS, Centrale Marseille, iSm2, Marseille, France \\ Email: \\ Jean-Marc R. Mattalia - jean-marc.mattalia@univ-amu.fr \\ Keywords: \\ a-aminonitrile; decyanation; electron donor; hydride; malononitrile; \\ transition metal catalysis \\ Beilstein J. Org. Chem. 2017, 13, 267-284. \\ doi:10.3762/bjoc. 13.30 \\ Received: 20 October 2016 \\ Accepted: 25 January 2017 \\ Published: 13 February 2017 \\ Associate Editor: J. A. Murphy \\ (C) 2017 Mattalia; licensee Beilstein-Institut. \\ License and terms: see end of document.
}

\begin{abstract}
This review presents an overview of the reductive decyanation reaction with a special interest for recent developments. This transformation allows synthetic chemists to take advantages of the nitrile functional group before its removal. Mechanistic details and applications to organic synthesis are provided.
\end{abstract}

\section{Introduction}

Many strategies in organic synthesis involve the removal of a beneficial functional group. The electron-withdrawing properties of the nitrile functional group appear beneficial in a variety of reactions [1,2]. This group coordinates metal complexes and can be used as a directing group for $\mathrm{C}-\mathrm{H}$ bond activation reactions catalyzed by transition metals [3-6]. The $\alpha$-deprotonation of alkylnitriles generates active $\alpha$-cyano carbanion nucleophiles. Recent investigations have resulted in different modes of alkylnitrile activations and in the development of new catalytic cyanoalkylation methodologies [7]. While Fleming and Zhang first focused on the removal of the cyano group from cyclic substrates [8], in 2006 we published a review reporting various methods allowing the reductive decyanation reaction that transforms organic nitriles into the parent alkane [9]. Even if chemical procedures previously described are still of relevance in organic synthesis, it is noteworthy that new methods have now emerged with the aim to develop mild reaction conditions that allow reduction of a wide scope of substrates and tolerate a variety of functional groups. This review attempts to be complementary to the paper published in 2006 and proposes an overview of the reductive decyanation reaction that focuses on more modern methods.

\section{Review}

\section{Alkali-metal-promoted decyanation}

Since the article by Arapakos in 1967 [10], decyanations using alkali metal dissolving conditions, typically $\mathrm{Li}$ or $\mathrm{Na} / \mathrm{NH}_{3}$, are widely used in organic synthesis [11-15]. The mechanism proposed involves an electron transfer with formation of a radical anion intermediate, and then a cyanide anion is eliminated with 
concomitant formation of a radical. The latter is then reduced to a carbanion which can be in situ protonated by ammonia or, depending on the conditions used, another proton source (Scheme 1).

Using $\mathrm{Na} / \mathrm{NH}_{3}$ or $\mathrm{Li} / \mathrm{EtNH}_{2}$ solutions, Arapakos obtained the best yields for the decyanation of phenyl-substituted acetonitriles, tertiary alkyl, and aromatic nitriles. However, primary and secondary nitriles also led to the reduction to the amine $[10,16]$. This drawback can be overcome using K/HMPA/ $t$-BuOH $[17,18]$ or $\mathrm{K} /$ dicyclohexano-18-crown-6/toluene $[19,20]$. In the latter case, the toluene radical anion is believed to be the reactive species. LiDBB (lithium di-tert-butylbiphenylide) and Li naphthalenide are also common electron donors $[15,21,22]$. Because of the mechanism described in Scheme 1, the nature of the medium and the substrate strongly influence the course of the reaction. Then, in the absence of a proton source, the organolithium intermediate can cyclize or react with an electrophile giving the expected coupling products [23-27]. Metal dissolving conditions allow the reduction of various other functional groups [28]. Rychnovsky took advantage of this reactivity and achieved reductive decyanations with concomitant Birch reduction or benzyl ether cleavage [29-31]. An example related to the synthesis of polyene macrolides is described in Scheme 2 .
Rojas et al. proposed a convenient two-step pathway for the preparation of alkyl $\alpha, \omega$-dienes 3 . These dienes are well-known precursors in ring-closing metathesis (RCM) and acyclic diene metathesis (ADMET) chemistry [32]. They first reported the quantitative $\alpha$-alkylation of primary nitriles $\mathbf{1}$ [33]. In a second part of their work, they developed adequate conditions to carry out the decyanation reaction without olefin isomerization [18]. They explored several methods for the preparation of 12-butyltricosa-1,22-diene $3\left(\mathrm{R}=n-\mathrm{C}_{4} \mathrm{H}_{9}\right)$. The reaction was carried out in a slurry of $\mathrm{K} / \mathrm{Al}_{2} \mathrm{O}_{3}$ in hexane, hexane/toluene (1:1) and toluene giving $20 \%, 63 \%$ and $75 \%$ of olefin isomerization (from NMR and GC), respectively, for each solvent [34]. This isomerization was attributed to the translocation of the tertiary radical intermediate to a more stable allyl radical leading to the double bond migration. This rearrangement was avoided using $\mathrm{K} /$ $\mathrm{Ph}_{3} \mathrm{CH}$ in hexane/ether $\left(3 \mathrm{R}=n-\mathrm{C}_{4} \mathrm{H}_{9}, 41 \%\right.$ yield $)$ or $\mathrm{K} / \mathrm{HMPA} /$ $t$-BuOH in ether $\left(3 \mathrm{R}=n-\mathrm{C}_{4} \mathrm{H}_{9}, 99 \%\right.$ yield $)$. The latter optimized conditions allow the decyanation of alkylcyano $\alpha, \omega-$ dienes $\mathbf{2}$ in quantitative yields with no detection of olefin isomerization (Scheme 3).

Radical intermediates were trapped using the radical probe $\mathbf{4}$ (Scheme 4). Replacing $t$-BuOH with $t$-BuOD in Scheme 3 ( $\mathrm{R}=\mathrm{CH}_{3}$ case), yielded the decyanation product 3 with $92 \%$ deuterium incorporation. With respect to the mechanism de-

$$
\mathrm{RCN} \stackrel{\mathrm{e}^{-}}{\longrightarrow} \mathrm{RCN}^{-} \underset{{ }_{-} \mathrm{CN}}{\longrightarrow} \mathrm{R}^{\cdot} \stackrel{\mathrm{e}^{-}}{\longrightarrow} \mathrm{R}^{-} \stackrel{\mathrm{H}^{+}}{\longrightarrow} \mathrm{RH}
$$

Scheme 1: Mechanism for the reduction under metal dissolving conditions

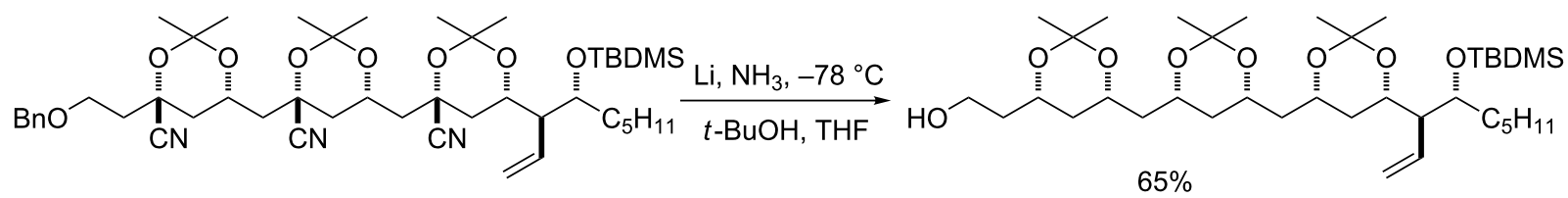

Scheme 2: Example of decyanation in metal dissolving conditions coupled with deprotection [30]. TBDMS = tert-butyldimethylsilyl.

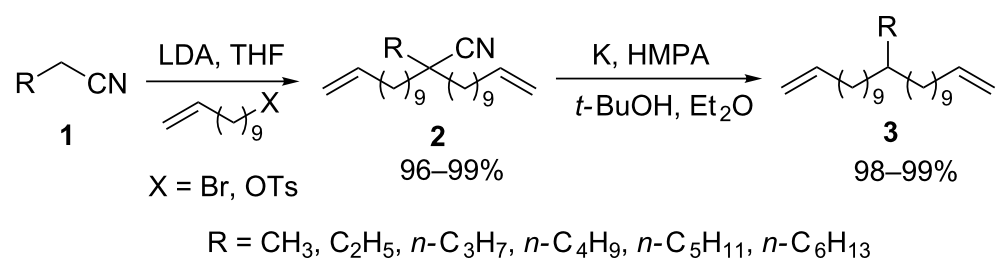



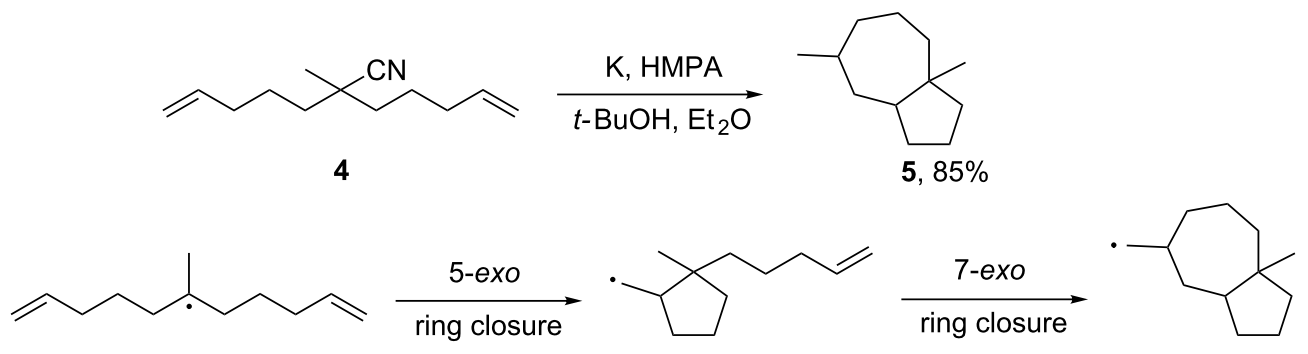

Scheme 4: Cyclization reaction using a radical probe [18]

scribed in Scheme 1, the authors suggest that $t-\mathrm{BuOH}$ (or $\mathrm{Ph}_{3} \mathrm{CH}$ ) could act as $\mathrm{H}$-atom donor that quenches the radical intermediate. However, this interpretation is opened to discussion because olefin functionalities also can undergo isomerization via anionic intermediates [35] and radicals usually abstract hydrogen atoms preferentially from the alkyl groups of $t \mathrm{BuOH}$ [36-38]. Therefore $t$ - $\mathrm{BuOH}$ could act as a proton donor and so prevent the olefin isomerization.

Alkali metals can also be used in suspension. As mentioned above, highly dispersed potassium over neutral alumina $\left(\mathrm{K} / \mathrm{Al}_{2} \mathrm{O}_{3}\right)$ in hexane is able to effect the reductive cleavage of alkylnitriles [18,34]. Zárraga et al. described an efficient synthesis of $( \pm$ )-xanthorrhizol (8) [39]. The authors prepared the intermediate 7 by dialkylation of $\mathbf{6}$ and attempted to carry out a one-pot decyanation and demethylation [40] with a suspension of lithium in THF. The target compound 8 was obtained in $74 \%$ yield together with $24 \%$ of the byproduct 9 (Scheme 5). This compound seems to be formed by a cross-linked ether cleavage of the methoxy group induced by the anion intermediate resulting from the decyanation pathway (Scheme 1). The authors increased the yield to $99 \%$ by adding $\mathrm{NH}_{4} \mathrm{Cl}$ as proton source that immediately reacts with the anion before the ether cleavage.

\section{Aluminium- and borohydrides and the use of sodium hydride \\ Reduction of $\alpha$-aminonitriles}

Bifunctional $\alpha$-aminonitriles exhibit several modes of reactivity. Recent reviews demonstrated the richness of this chemistry and emphasized synthetic applications particularly in heterocyclic chemistry [41-44]. The reductive decyanation of $\alpha$-aminonitriles under metal dissolving conditions is a common procedure that proceeds through a two-electron-transfer pathway (Scheme 1) $[23,44]$. In the ionic pathway, the loss of the cyanide ion yields an iminium cation that can be reduced by various hydride donors (Scheme 6). Alternatively, secondary amines could involve an elimination of $\mathrm{HCN}$ and reduction of the formed imine.

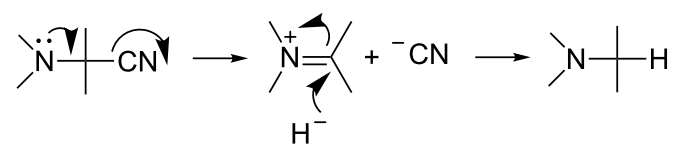

Scheme 6: Mechanism for the reduction of $\alpha$-aminonitriles by hydride donors.

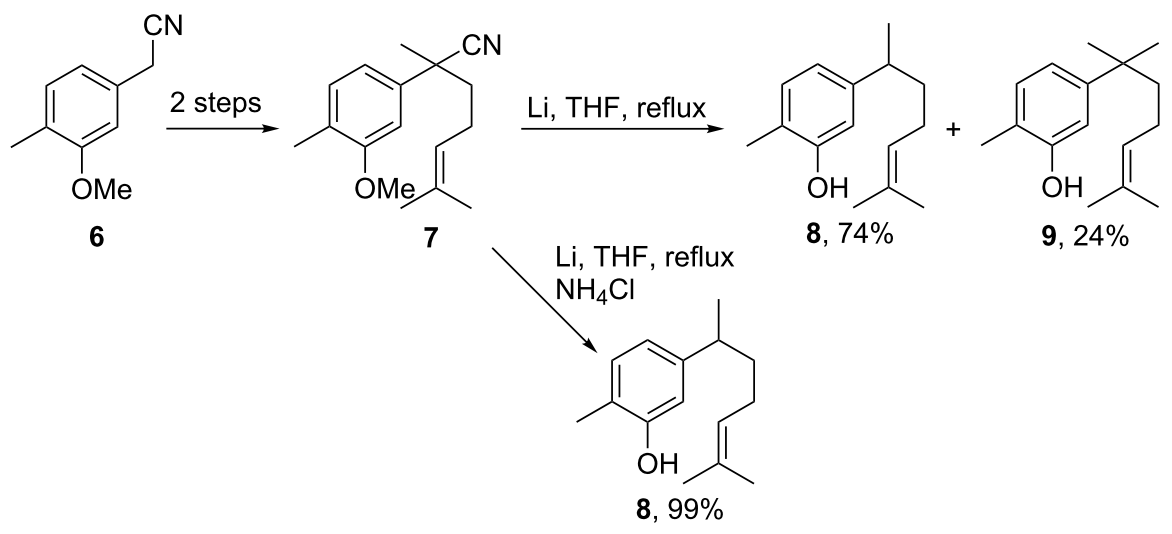


$\mathrm{NaBH}_{4}$ [45-51] or $\mathrm{NaBH}_{3} \mathrm{CN}$ [47,52-59] are widely used hydride donors and, less frequently, $\mathrm{BH}_{3}[60,61], \mathrm{AgBF}_{4} /$ $\mathrm{Zn}\left(\mathrm{BH}_{4}\right)_{2}[62-64]$ or $\mathrm{LiAlH}_{4}[65,66]$. These reactions usually require mild conditions but the course of the reaction depends on the ease of formation of the iminium ion [48,67-69]. With the highly reactive $\mathrm{LiAlH}_{4}$, diamines can also be formed by reduction of the nitrile moiety [70]. This competition with the decyanation reaction depends on the structure of the $\alpha$-aminonitrile, stereoelectronic effects and internal strain of the molecule [68].

Chuang et al. prepared a set of $\alpha$-aminoacrylonitriles $\mathbf{1 1}$ by a cyano-promoted aza-Diels-Alder cycloaddition [71]. The cyano groups were then removed in high yields by treatment with $\mathrm{NaBH}_{4}$ in 2-propanol by using both basic and nucleophilic properties of the hydride ion. The proposed mechanism involves a double-bond isomerization to the $\alpha$-aminonitrile intermediate which is then reduced by the hydride ion in a classical way (Scheme 7). Interestingly, deuterium-labelling experiments indicate that one of the methylene hydrogens of the formed allylamine $\mathbf{1 2}$ is derived from the protic solvent and the other comes from the reducing agent. Finally, an oxidative aryl-aryl coupling promoted by vanadium oxytrifluoride $\left(\mathrm{VOF}_{3}\right)$ afforded phenanthroindolizidines $(\mathbf{1 3}, n=1)$ and phenanthroquinolizidines $(\mathbf{1 3}, n=2)$. Anticancer activities of these 18 compounds were evaluated against three human cancer cell lines.
$\mathrm{BH}_{3} \cdot \mathrm{THF}$ containing $\mathrm{NaBH}_{4}$ has been used for the reduction of diimines [72,73] and was studied in-depth by Zhang and co-workers in the reductive decyanation reaction. In their work, the cyano group activates the $[3+2]$ cycloaddition of azomethine ylides and is then removed to yield 5-unsubstituted pyrrolidines [74]. These substructures appear in several biologically active natural products and drugs [75]. A range of decyanation conditions were screened such as $\mathrm{NaBH}_{4}$ in THF or $\mathrm{MeOH}, \mathrm{NaBH}_{4} / \mathrm{AgBF}_{4}$ in THF and $\mathrm{NaBH}_{3} \mathrm{CN}$ in $\mathrm{MeOH} /$ $\mathrm{AcOH}$. They also explored $\mathrm{BH}_{3}$ alone in THF and with varying amounts of $\mathrm{NaBH}_{4}$. They found that the addition of a catalytic amount of $\mathrm{NaBH}_{4}$ was very efficient for the reductive decyanation reaction. Scheme 8 shows the scope of this two-step transformation. This protocol is successfully used with various electron-deficient substituted phenyl groups $(\mathbf{1 5 b}-\mathbf{e})$ and with heterocycles $(\mathbf{1 5 f}-\mathbf{h})$. The double-bond of cyanopyrrolidine $\mathbf{1 4 l}$ is preserved from the hydroboration reaction (15l). Olefins bearing bulky ester, sulfone or amide groups afforded good to excellent yields (15i-k). A series of aliphatic $\alpha$-iminonitriles also gave good results $(\mathbf{1 5 n}, \mathbf{0})$. Notably the labile dimethylacetal group tolerates this two-step transformation $(\mathbf{1 5 m})$.

Using this protocol, the authors described a total synthesis of ( \pm )-isoretronecanol (19), a pyrrolizidine alkaloid (Scheme 9). In this case the two-step protocol is followed by a lactamization and the one-pot reduction of ester and lactam groups of 18.

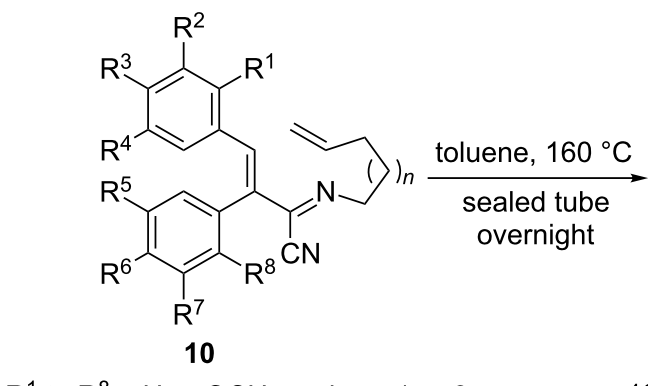<smiles>[R]c1cc(C2=C(N)N3CCCC3CC2c2cc([R])c([R])c([R])c2[R])c([R])c([R])c1[R]</smiles>

$\mathrm{R}^{1}$ to $\mathrm{R}^{8}=\mathrm{H}$ or $\mathrm{OCH}_{3}$ and $n=1$ or 2

18 examples, $60-93 \%$ yields<smiles>[R]c1cc(C2=C(c3cc([R7])c([R])c([R])c3[R])CN3CCCC3C2)c([R7])c([R])c1[R]</smiles>

18 examples, $92-100 \%$ yields

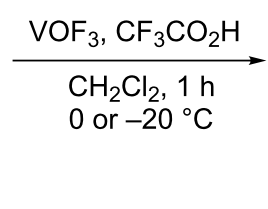

18 examples, $54-92 \%$ yields 


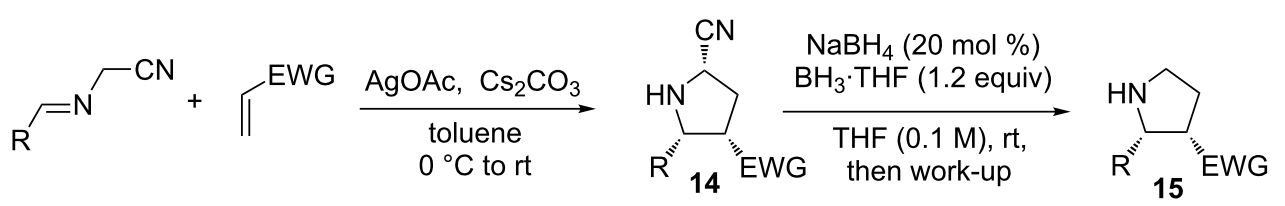

endo/exo $>20: 1$

(14d endo/exo 14:1)<smiles>CC(=O)OC1CCN[C@@H]1c1ccccc1</smiles>

15a $\mathrm{R}^{\prime}=\mathrm{H}, 92 \%$ and $91 \%$

$15 \mathrm{~b} \mathrm{R}^{\prime}=p-\mathrm{Br}, 95 \%$ and $94 \%$

15c $\mathrm{R}^{\prime}=0-\mathrm{Br}, 85 \%$ and $80 \%$

15d $\mathrm{R}^{\prime}=m-\mathrm{Br}, 87 \%$ and $90 \%$

$15 e \mathrm{R}^{\prime}=p-\mathrm{CF}_{3}, 84 \%$ and $93 \%$

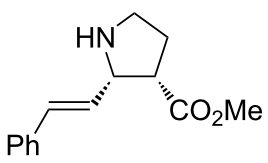

$15 \mathrm{I}, 64 \%$ and $76 \%$<smiles></smiles>

$15 f \mathrm{X}=0,74 \%$ and $65 \%$

$15 \mathrm{~g} X=\mathrm{S}, 91 \%$ and $80 \%$

$15 \mathrm{~h} X=\mathrm{NBoc}, 88 \%$ and $87 \%$<smiles>COC(C)CC[C@H]1NCC[C@@H]1C(C)=O</smiles>

$15 \mathrm{~m}, 83 \%$ and $69 \%$<smiles>N#CC1CCNC1c1ccccc1</smiles>

15i EWG $=\mathrm{SO}_{2} \mathrm{Ph}, 68 \%$ and $87 \%$

15j $E W G=\mathrm{CO}_{2} t-\mathrm{Bu}, 86 \%$ and $91 \%$

15k EWG $=\mathrm{CON}(\mathrm{OMe}) \mathrm{Me}, 90 \%$ and $84 \%$<smiles>[R]C1NCCC1C(C)=O</smiles>

15n $\mathrm{R}=n-\mathrm{C}_{7} \mathrm{H}_{15}, 81 \%$ and $88 \%$ $150 \mathrm{R}=t-\mathrm{Bu}, 88 \%$ and $79 \%$

Scheme 8: Two-step synthesis of 5-unsubstituted pyrrolidines (25 examples and 1 synthetic application, see below). The two yields refer successively to the cycloaddition (14) and decyanation (15) steps [74]. Boc = tert-butoxycarbonyl. EWG = electron-withdrawing group.
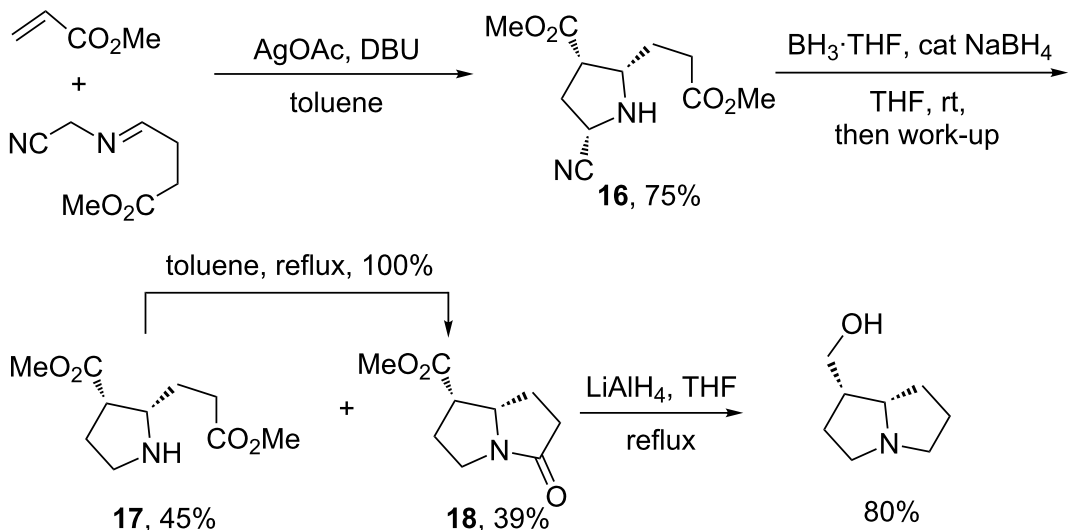

( \pm )-isoretronecanol 19

Scheme 9: Synthesis of ( \pm )-isoretronecanol 19. DBU = 1,8-diazabicyclo[5.4.0]undec-7-ene [74].

The authors proposed a reductive anionic chain mechanism described in Scheme 10. The exposure of $\mathbf{1 4 a}$ to $\mathrm{BH}_{3}$ generates a borane-amine complex $\mathbf{2 0}$ whose fragmentation could be promoted by $\mathrm{NaBH}_{4}$. The resulting imine 21 is reduced by $\mathrm{BH}_{3}$ with the help of the cyanoborohydride anion. The formed anion $\mathbf{2 2}$ abstracts a proton from complex $\mathbf{2 0}$ to produce $\mathbf{2 3}$ or $\mathbf{2 4}$ and regenerate $\mathbf{2 1}$ and $\mathrm{BH}_{3} \mathrm{CN}^{-}$. A set of experiments supports this proposal. Notably, borane is the major hydride source for the reduction and $\mathbf{2 2}$ (derived from the reaction of $\mathbf{2 3}$ and $\mathrm{NaH}$ ) is efficient for this chain reaction. Stable intermediates $\mathbf{2 3}$ and $\mathbf{2 4}$ were fully characterized while the unstable complex $\mathbf{2 0}$ was only characterized with ${ }^{1} \mathrm{H}$ NMR.

\section{Reduction of other substrates}

The reductive decyanation promoted by aluminium- and borohydrides for substrates other than $\alpha$-aminonitriles has been de- 


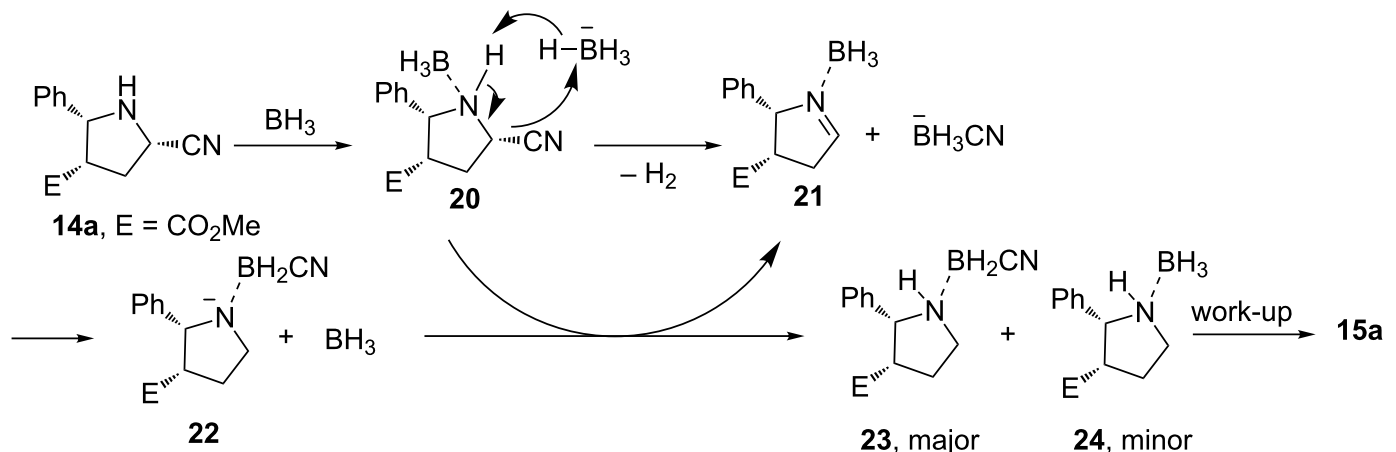

Scheme 10: Proposed mechanism with 14a for the $\mathrm{NaBH}_{4}$ induced decyanation reaction ("BH 3 " $\left.=\mathrm{BH}_{3} \cdot \mathrm{THF}\right)[74]$.

scribed for more specific cases and usually displays moderate yields [76-79]. Recently, the DIBAL-H-induced decyanation of gem-dicyanodihydroazulene derivatives was described but only poor yields were reported [80].

Chiba et al. accidently discovered the reductive decyanation of aryl substituted tertiary nitriles (Scheme 11) [81]. The protocol involves $\mathrm{NaH}$ in THF in the presence of $\mathrm{LiI}$ at $85{ }^{\circ} \mathrm{C}$ and appears suitable for the construction of the important 1,1-diarylalkane $(\mathbf{2 6} \mathbf{k}-\mathbf{m})$ and triarylmethane (26n) derivatives. Strained cyclobutylarenes $(\mathbf{2 6 g}, \mathbf{h})$ and heterocycles $(\mathbf{2 6} \mathbf{i}, \mathbf{j})$ are prepared in this way and the electron-rich 4-methoxyphenyl group decreases the reaction rate (compare 26e,g with $\mathbf{2 6 f}, \mathbf{h}$ ). The decyanation of nitriles with the NaH-NaI system gives comparable yields but much longer reaction times are generally required.

The reduction of radical probes (no rearranged products formed from $25 \mathbf{d}, \mathbf{1}, \mathbf{m}$ ) and deuterium-labelling experiments (no deuterium incorporation using THF- $d_{8}$ and quenching with $\mathrm{D}_{2} \mathrm{O}$ ) discard the possibility of a single-electron transfer pathway. Other reductions suggest a hydride addition with formation of an iminyl anion intermediate. Particularly, when the reaction of $\mathbf{2 5 f}$ was quenched after $2.5 \mathrm{~h}$, the corresponding

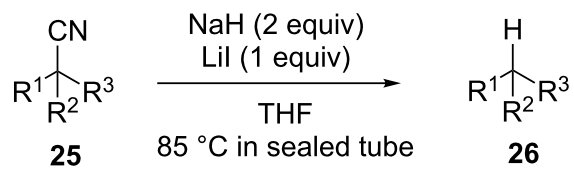<smiles>COc1ccc(CC(c2ccccc2)c2ccccc2)cc1</smiles>

26a, 96\%, $3 \mathrm{~h}$<smiles>[R]c1ccc(C2CCCCC2)cc1</smiles>

26e $\mathrm{R}=\mathrm{Cl}, 81 \%, 2.5 \mathrm{~h}$

26f $\mathrm{R}=\mathrm{OMe}, 92 \%, 24 \mathrm{~h}$<smiles>[CH2]C(Cc1ccc(OC)cc1)c1cccc(F)c1</smiles>

26b, $97 \%, 3 \mathrm{~h}$<smiles>[R]c1ccc(C2CCC2)cc1</smiles>

26g $\mathrm{R}=\mathrm{Ph}, 85 \%, 2.5 \mathrm{~h}$

26h R = OMe, 70\%, $32 \mathrm{~h}$<smiles>CC(C)c1ccc2ccccc2c1</smiles>

26c, $90 \%, 2 \mathrm{~h}$<smiles>c1ccc(C2CCOCC2)cc1</smiles>

$26 \mathbf{i}, 81 \%, 3 \mathrm{~h}$ 26j, $87 \%, 7 \mathrm{~h}$<smiles>C=CCCCCCCCC=C</smiles>

26d, $98 \%, 2$ h<smiles>c1ccc(C2CCCCC2)nc1</smiles><smiles>COCCC(c1ccccc1)c1ccccc1</smiles>

26k, 99\%, 10 h<smiles>C=CCCCC(c1ccccc1)c1ccccc1</smiles>

26I, 99\%, $19 \mathrm{~h}$<smiles>COc1ccc(C(c2ccccc2)C2CC2)cc1</smiles>

$26 \mathrm{~m}, 99 \%, 10 \mathrm{~h}$ 
aldehyde was formed in $42 \%$ yield together with $37 \%$ of the decyanated product $\mathbf{2 6 f}$.

DFT calculations conducted on nitrile 250 support the hydride addition to the $\mathrm{CN}$ triple bond with formation of an iminyl anion intermediate $\mathbf{2 7}$. The latter easily isomerizes to its isomer $\mathbf{2 8}$ where a sodium cation- $\pi$-interaction occurs. The last step involves a $\mathrm{C}-\mathrm{C}$ bond cleavage and proton transfer with elimination of $\mathrm{NaCN}$ (Scheme 12). This proton transfer occurs with retention of configuration as experimentally observed. Indeed, the kinetic profiles show that the decyanation reactions include an induction period $(0.5 \mathrm{~h}$ and $2 \mathrm{~h}$, respectively, for $\mathrm{NaH}-\mathrm{LiI}$ and $\mathrm{NaH}-\mathrm{NaI}$ systems) suggesting the formation of a new inorganic composite. These materials consist of metal iodide interspersed with activated $\mathrm{NaH}$ resulting in an unique hydridedonor reactivity [82]. An addition-elimination mechanism has been previously proposed for the $\mathrm{LiAlH}_{4}$ promoted decyanation of 2,2-diphenylpropionitrile and related nitriles. In such pathways, the phenyl groups probably favor the $\mathrm{C}-\mathrm{C}$ bond cleavage by stabilizing the incipient negative charge on the carbon adjacent to the cyano group [76,77].

\section{Transition-metal-catalyzed reductive decya- nation}

\section{Hydrogenation of $\alpha$-aminonitriles}

The decyanation of $\alpha$-aminonitriles with hydrogen present in an excess of Raney nickel was described by Husson and co-workers on oxazolidine derivatives $[83,84]$. The authors logically proposed that the decyanation occurred via the reduction of an iminium ion intermediate. The hydrogenation of $\alpha$-aminonitriles catalyzed by nickel nanoparticles results in reductive decyanation and yields 29-31. The colloid solution of nickel is prepared in situ via reduction of anhydrous $\mathrm{NiCl}_{2}$ with $\mathrm{NaBH}_{4}$ in $t$-BuOH, iPrOH or $n$-butanol, the reactions are then performed upon bubbling of hydrogen at atmospheric pressure through the reaction mixture (Scheme 13). The reductive decyanation of 2-hydroxyadamantane-2-carbonitrile is successful by this method and yields alcohol 32 [85].

For less reactive nitriles, the $\mathrm{C}-\mathrm{CN}$ bond cleavage usually requires hydrogen under pressure and high temperatures [86].

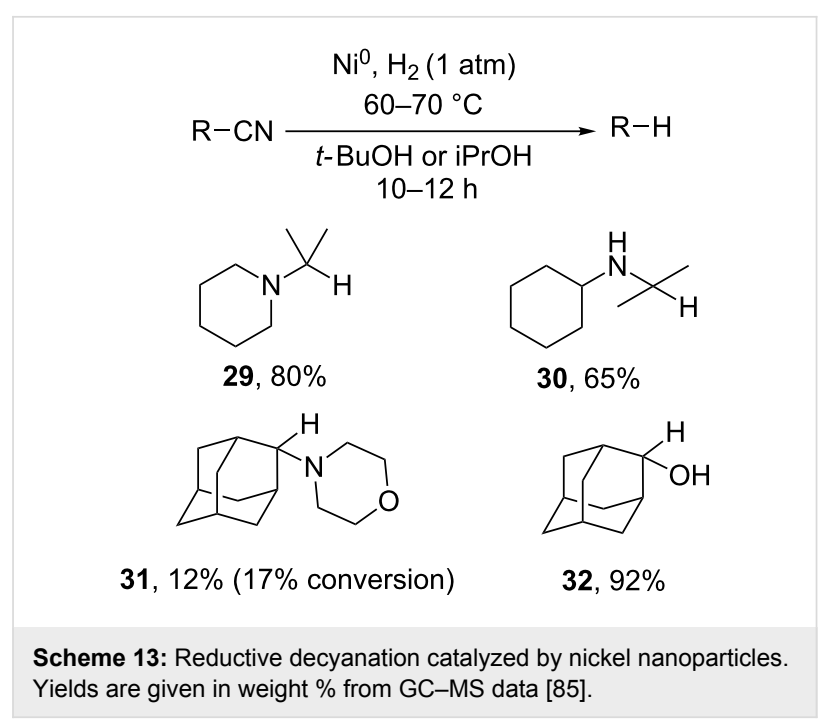

Tao et al. reported the decyanation of 2-cyanobenzo[b]thiophene using hydrogen and $\mathrm{Pd}, \mathrm{Pt} / \mathrm{TiO}_{2}$ or $\mathrm{Pd} / \mathrm{TiO}_{2}-\mathrm{Cu}$ as catalyst at $200-300{ }^{\circ} \mathrm{C}$ with yields varying from 79 to $90 \%$ (Scheme 14) [87].

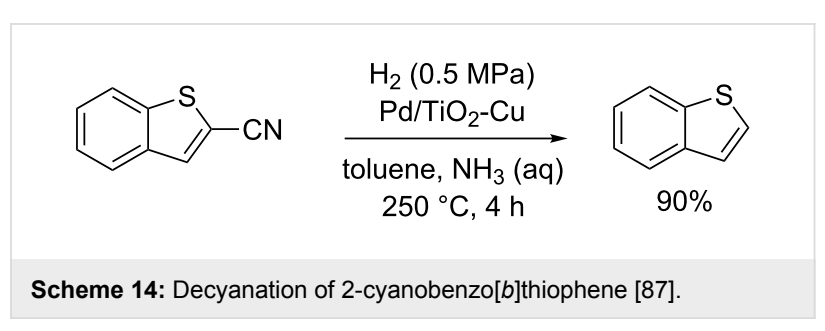

Opatz et al. developed the enantioselective syntheses of various alkaloids using the rhodium catalyst developed by Noyori [88] for the asymmetric transfer hydrogenation of imines. Interestingly, imines are formed from unstable $\alpha$-aminonitrile intermediates which spontaneously eliminate HCN [89-91].

\section{Iron-catalyzed reductive decyanation}

In 1982, Yamamoto et al. disclosed the $\mathrm{C}-\mathrm{CN}$ bond cleavage promoted by an electron-rich cobalt complex [92]. Since that time, the activation of inert $\mathrm{C}-\mathrm{CN}$ bonds by transition metals has been widely investigated. Improvements towards mild and

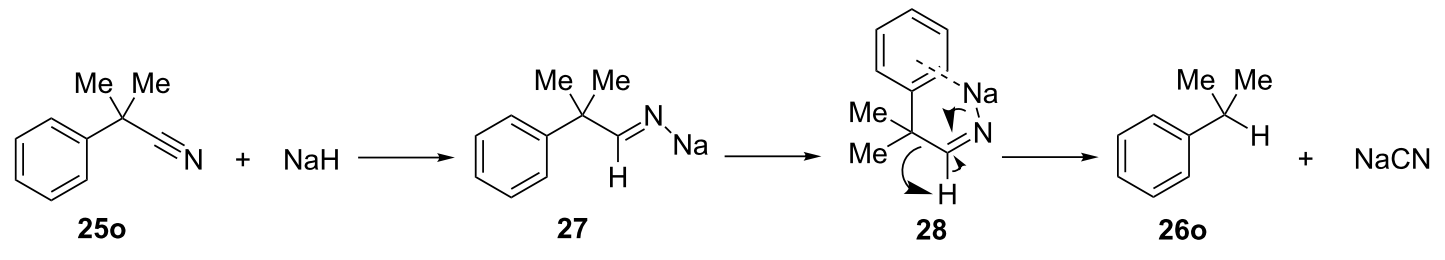




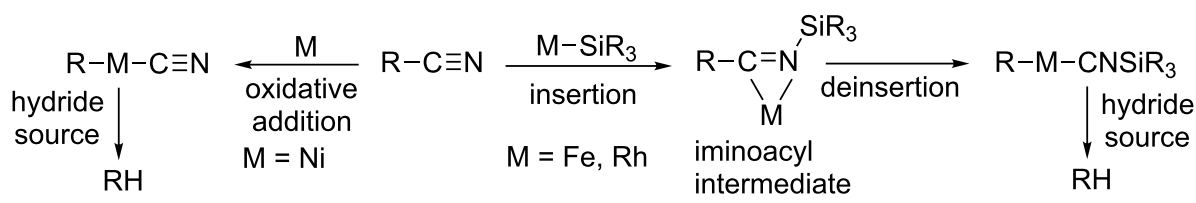

Scheme 15: Simplified pathways involved in transition-metal-promoted reductive decyanations $[93,95]$.

green conditions with a large substrate scope have been achieved in many reactions including decyanation. Several reviews account for the richness of this chemistry [93-99]. Two major pathways for the $\mathrm{C}-\mathrm{CN}$ bond activation have emerged (Scheme 15). One is the oxidative addition of the $\mathrm{C}-\mathrm{CN}$ bond to a low-valent metal center (Ni case). The other pathway involves a silylmetal-assisted carbon cyano bond cleavage through an iminoacyl intermediate ( $\mathrm{Rh}, \mathrm{Fe}$ cases). In both pathways, the combination with a reducing agent gives a catalytic reductive system for the removal of the cyano group.

The discussion below on transition-metal-catalyzed reactions focuses on selected examples that show the wide scope of reduced substrates including alkyl cyanides, challenging substrates due to their propensity to undergo $\beta$-hydride elimination from alkylmetal intermediates. Nakazawa et al. reported the photoinduced $\mathrm{C}-\mathrm{CN}$ bond cleavage catalyzed by iron complexes of a few primary alkyl cyanides and aryl cyanides in the presence of $\mathrm{Et}_{3} \mathrm{SiH}[100,101]$. Decyanated species were formed together with silyl cyanide. Both aliphatic and aromatic nitriles were successfully reduced (Scheme 16) but an electron-withdrawing, bulky or coordinating substituent on the $\mathrm{C}$ atom linked to the cyano group disfavors the reductive decyanation.

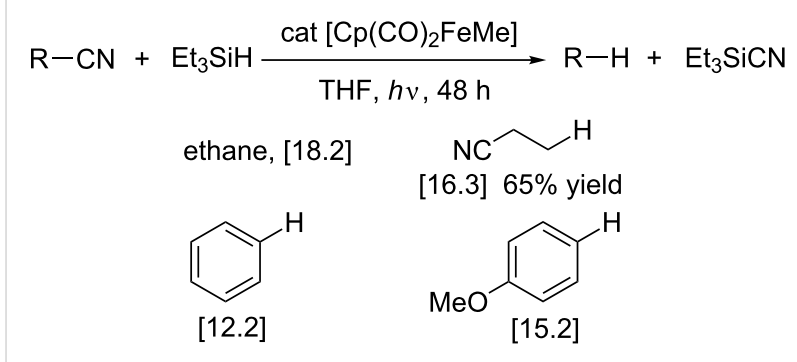

Scheme 16: Fe-catalyzed reductive decyanation. Numbers in square brackets represent turnover numbers. The TONs were determined by $\mathrm{GC}$ and based on the amount of $\mathrm{Et}_{3} \mathrm{SiCN}$ produced (10 examples with TON > 4) [100]. Cp = cyclopentadienyl.

\section{Rhodium-catalyzed reductive decyanation}

Chatani and co-workers have investigated the rhodium-catalyzed carbon-cyano bond cleavage reactions using organosilicon reagents [94]. They reported a rhodium-catalyzed reductive decyanation with a hydrosilane as reducing agent. They selected $[\mathrm{RhCl}(\operatorname{cod})]_{2}$ (cod $=1,5$-cyclooctadiene $)$ as catalyst and found that the use of triisopropylsilane and $\mathrm{P}(\mathrm{OBu})_{3}$ or $\mathrm{P}(\mathrm{OiPr})_{3}$ as ligands led to the best results [102,103]. Aryl, heteroaryl (Scheme 17), benzyl and alkyl cyanides (Scheme 18) are applicable to this decyanation reaction.

$$
\begin{array}{cc}
\mathrm{Ar}-\mathrm{CN}+\underset{\mathrm{H}-\mathrm{Si}(\mathrm{iPr})_{3}}{2 \text { equiv }} & \stackrel{[\mathrm{RhCl}(\mathrm{cod})]_{2}(5 \mathrm{~mol} \%)}{\mathrm{P}(\mathrm{OBu})_{3}(10 \mathrm{~mol} \%)} \\
{ } } \\
130^{\circ} \mathrm{C}, 15 \mathrm{~h}
\end{array} \mathrm{Ar}-\mathrm{H}
$$<smiles>[R]c1ccc2ccccc2c1</smiles>

33a, $R=H, 99 \%(G C)$<smiles>Cc1cccc(C)c1</smiles>

36, $81 \%$, run at $160{ }^{\circ} \mathrm{C}$ using $[\mathrm{RhCl}(\operatorname{cod})]_{2}(10 \mathrm{~mol} \%)$ and $\mathrm{P}(\mathrm{OiPr})_{3}(20 \mathrm{~mol} \%)$<smiles>CC1(C)OB(c2ccccc2)OC1(C)C</smiles>

$35,94 \%$

34a $\mathrm{R}=\mathrm{H}, 34 \mathrm{~b} \mathrm{R}=\mathrm{NMe}_{2}, 34 \mathrm{c} \mathrm{R}=\mathrm{OMe}$, 34d $\mathrm{R}=\mathrm{CO}_{2} \mathrm{Et}$, 34e $\mathrm{R}=\mathrm{NMeCOMe}$ $74-85 \%$ for $34 b-e$ (GC for $34 b-c)$<smiles>c1ccc2ccccc2c1</smiles>

$37,48 \%$

$38,81 \%$, run at $100^{\circ} \mathrm{C}$,<smiles></smiles>
in the absence of $\mathrm{P}(\mathrm{OBu})_{3}$ 


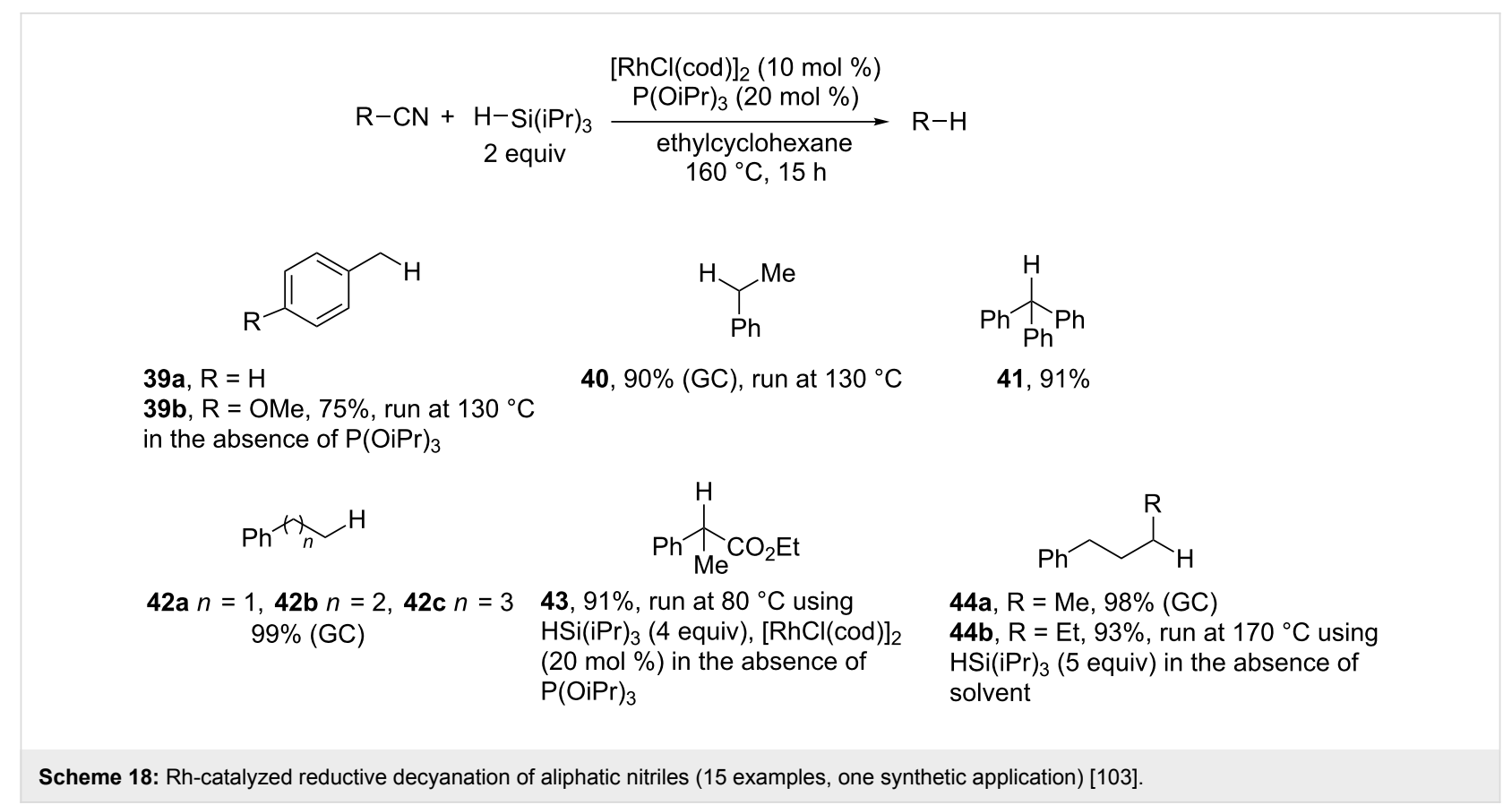

The use of hydrosilane as a mild reducing agent allows a high functional group tolerance $(\mathbf{3 4 b}-\mathbf{e}, \mathbf{3 5}, \mathbf{3 9 b}, \mathbf{4 3})$ and sterically hindered cyano groups are successfully removed $(\mathbf{3 6}, \mathbf{4 1}, \mathbf{4 3})$. Reactions of benzyl cyanides proceed smoothly even in the absence of the phosphite ligands $(\mathbf{3 9 b}, \mathbf{4 3})$. Interestingly, an ester group in the $\alpha$-position increases the reactivity (43). The reaction works well with simple primary and secondary alkyl cyanides but requires a higher reaction temperature. Aliphatic nitriles containing $\beta$-hydrogen atoms are successfully reduced $(40,42 a-c, 43,44 a)$. Even if alkenes are not formed, the authors show the occurrence of a $\beta$-hydride elimination/ hydrometalation sequence. However, the reduction of the more hindered substrate $\mathbf{4 4 b}$ requires a larger excess of hydrosilane to prevent the formation of alkene. Finally, unactivated tertiary alkyl cyanides lead to a complex mixture.

\section{Nickel-catalyzed reductive decyanation}

Maiti et al. established that the $\mathrm{Ni}(\mathrm{acac})_{2}$ complex $(\mathrm{acac}=$ acetylacetonate) of $\mathrm{PCy}_{3}(\mathrm{Cy}$, cyclohexyl) in combination with TMDS (tetramethyldisiloxane) as hydride source can catalyze the reductive decyanation efficiently (method A, Scheme 19) [104]. The use of $\mathrm{AlMe}_{3}$ appeared beneficial by facilitating the oxidative addition of the $\mathrm{C}-\mathrm{CN}$ bond to $\mathrm{Ni}$. Soon after, the same team developed the use of cheaper, greener and milder hydrogen gas as the hydride source. They found that catalytic $\mathrm{Ni}(\mathrm{cod})_{2}$ in combination with $\mathrm{PCy}_{3}$ and $\mathrm{AlMe}_{3}$ under 1 bar pressure of $\mathrm{H}_{2}$ gas was the protocol of choice (method $\mathrm{B}$ ) [105] As well as the activation of the $\mathrm{C}-\mathrm{CN}$ bond, $\mathrm{AlMe}_{3}$ helps to remove and consume the $\mathrm{HCN}$ gas produced under the reaction conditions. These protocols were successfully applied to a wide range of nitriles containing various other functional groups (Scheme 19). The ether bonds (33b, 49), ester (45), hydroxy (39c) and keto groups (46) are tolerated. With method B, aryl cyanides with amide (54), trifluoromethyl (55) and fluoro groups $(\mathbf{4 7 c})$ are reduced in attractive yields. For substrates bearing dicyano groups, monodecyanation is the major pathway (47b) and decyanations are efficient with sterically demanding ortho-substituents $(\mathbf{5 4}, \mathbf{5 7})$ or with ortho-directing groups $(\mathbf{4 5}, \mathbf{4 8}, \mathbf{5 0})$. Aliphatic nitriles underwent decyanation without $\beta$-hydride elimination (42a, 52b, 53).

Enthaler et al. reported the application of nickel complex $\mathbf{5 8}$ as precatalyst and tert-butylmagnesium chloride as reducing agent (method A) in the decyanation of alkyl and aryl cyanides [106]. In the same year, to easily generate nickel hydride complexes, the authors explored the possibility to apply more reactive hydride donors such as $\mathrm{LiBH}_{4}$ (method B) $[107,108]$. Finally, after investigating the reaction conditions and a precatalyst screening, the conditions described in Scheme 20 were selected. With method B, lower catalyst loading and shorter reaction times are necessary. With method A, benzonitrile yields $51 \%$ of benzene (34a) and an increase in yield is obtained with the methoxy and methyl groups $(\mathbf{3 4 c}, \mathbf{5 9}, \mathbf{3 4} \mathbf{j}$ para). For some substrates, the replacement of $t$ - $\mathrm{BuMgCl}$ by $n$ - $\mathrm{Bu}_{2} \mathrm{Mg}$ improves the yield $(\mathbf{3 4 b}, \mathbf{c}, \mathbf{5 9})$. With method B, excellent yields are obtained for methoxy $(\mathbf{3 4 c}, \mathbf{5 9})$ and methyl substituted aryl cyanides $\mathbf{3 4 j}$ while with method A, changing the position of the methyl substituent from the para to the ortho or meta positions decreases the yield in toluene. Dimethylamino and thioether groups display a lower yield with method B $(\mathbf{3 4 b}, \mathbf{g})$ contrary to the tri- 


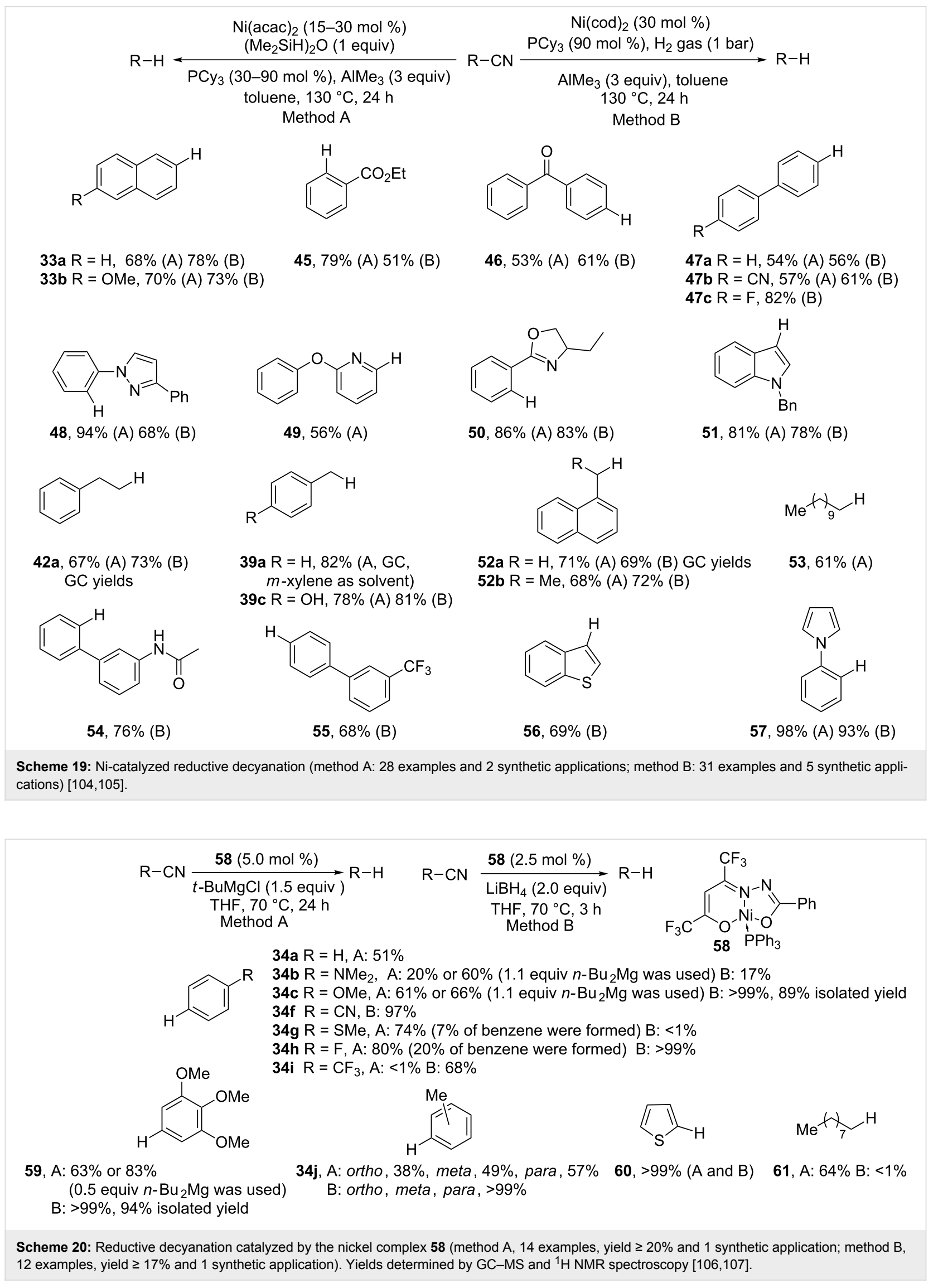


fluoromethyl group (34i). With $p$-fluorobenzonitrile the decyanation is observed with both methods (34h) but, with the bromo counterpart, dehalogenation also occurs. 2-Cyanothiophene results in quantitative yield of thiophene $\mathbf{6 0}$ with both methods but cyanopyridines are not converted, probably due to the coordination abilities of the pyridine. Finally, decanenitrile is decyanated with method A (61) but aliphatic nitriles are not converted to the desired product with method B.

Trapping of radicals with method A led the authors to propose the electron transfer mechanism described in Scheme 21. The complex 62 reacts with the Grignard reagent to form the nickelmagnesium hydride intermediate 64 via a $\beta$-hydride elimination from 63. A single-electron transfer (SET) to the nitrile oxidizes the complex at the metal center into $\mathbf{6 5}$ and generates an aryl radical. The electron can also be located in the ligand (noninnocent ligand, not represented in Scheme 21). Then, elimination of $\mathrm{MgXCN}$ and radical recombination with the nickel species produce 66. Finally, an elimination of Ar-H closes the catalytic cycle. A similar mechanism was proposed with method B.

\section{Radical reactions}

This part is related to radical reactions not involving alkali metals and focuses on the reduction of malononitriles and cyanoacetates ( $\alpha$-cyanoesters). These compounds are particularly versatile reagents in organic synthesis including multicompo- nent reactions [109-113]. However, like decarboxylation for related malonic ester or acetoacetates, an easy access to the removal of the cyano group should encourage future developments using these compounds.

\section{$\mathrm{Bu}_{3} \mathrm{SnH}$ and $\mathrm{N}$-heterocyclic carbene boranes}

The reductive decyanation of malononitriles to mononitriles using tributyltin hydride/AIBN in benzene was unexpectedly discovered by Curran and Seong [114]. Later, they made a full study and successfully reduced to mononitriles a variety of mono- and dialkylated malononitriles but under these conditions, the reduction of cyanoacetates failed [115]. Synthetic applications of this methodology were later described [116-118]. Chiba et al. have developed a concise and stereoselective methodology for the preparation of highly substituted carbocycles $[119,120]$. An example in described in Scheme 22. The 5-membered ring is formed via a $\mathrm{K}_{2} \mathrm{CO}_{3}$ mediated $\mathrm{S}_{\mathrm{N}} 2$ - conjugate addition sequence between malononitrile and 6-bromo-2hexenoate derivatives 67a,b. Dicyanocyclopentanes 68a,b are treated with tributyltin hydride/AIBN giving the monodecyanated products $69 \mathbf{a}, \mathbf{b}$. Bicyclic lactones 70a,b are then obtained in 3 steps in $41 \%$ and $51 \%$ yields, respectively, from 69a,b.

Later Curran's group discovered that NHC-boryl radicals, generated from NHC-boranes (N-heterocyclic carbene boranes), abstracted the cyano group from various organic nitriles and

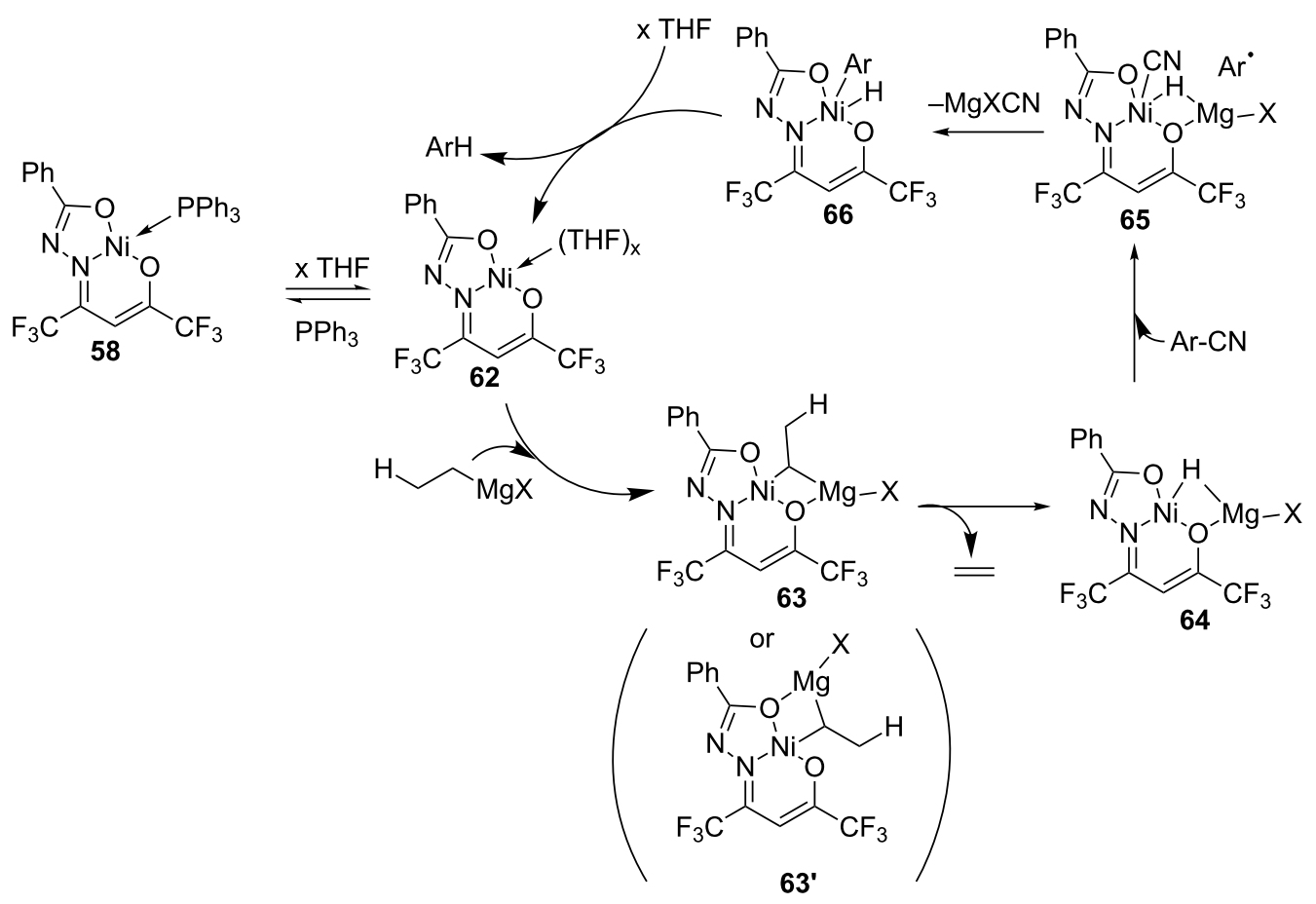

Scheme 21: Proposed catalytic cycle for the nickel complex 58 catalyzed decyanation (method A). Only the cycle for 63 is shown [106]. 


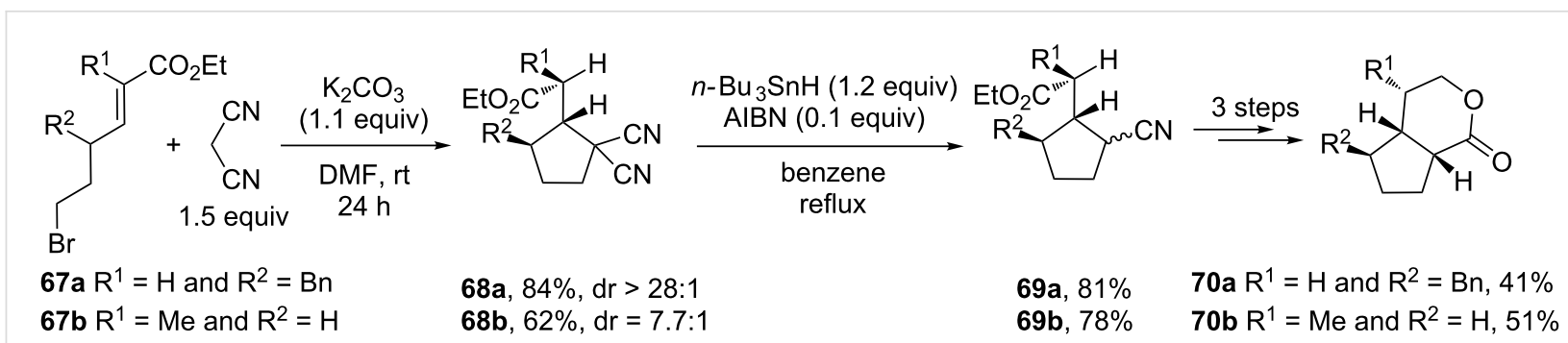

Scheme 22: Synthesis of bicyclic lactones $[119,120]$.

dinitriles and applied this reaction for the synthesis of new NHC-boryl nitrile and dinitrile compounds [121]. They observed that malononitrile was the most efficient donor to produce boryl nitriles and concluded that substituted malononitriles would be decyanated by NHC-boranes. For this transformation, malononitriles are reacting with a slight excess of NHC-borane 71, in refluxing $t$-BuOH with DTBP (di-tertbutylperoxide) as radical initiator. The yields are attractive while roughly comparable amounts of boryl nitriles $\mathbf{7 4}$ and $\mathbf{7 5}$ are formed (Scheme 23). Malononitriles 72d,e are successfully reduced to $\mathbf{7 3 d}, \mathbf{e}$ while with photoactivated $\mathbf{7 8}$ such substrates afforded complex mixtures (see below). Contrary to the reductive decyanation with $\mathrm{Bu}_{3} \mathrm{SnH}$ [115], the NHC borane reduces the $\alpha$-cyanoester $\mathbf{7 2 g}$ to $\mathbf{7 3 g}$ while the aryl chloride and bromide moieties are preserved $(\mathbf{7 3 h}, \mathbf{i})$.

The use of a 5-hexenyl radical probe led to the formation of $99 \%$ of cyclized products (relative yield). The authors proposed a radical chain mechanism similar to that proposed in the reaction with $\mathrm{Bu}_{3} \mathrm{SnH}$. While the tin radical was proposed to add to nitrogen [115], here the evidence points more to the addition of the boryl radical $\mathbf{7 6}$ on the nitrile carbon to form the nitrogen centered radical 77. $\beta$-Fragmentation leads to NHC-boryl nitrile 74 and a carbon centered radical. A hydrogen atom transfer reaction between the electrophilic $\alpha$-cyano radical and the nucleophile NHC-borane achieves the chain propagation (Scheme 24). The isolation of the NHC-boryl nitrile 74, EPR spectroscopy observations [122], and polar effects fit with this proposition.

\section{Neutral organic electron donors}

Powerful single-electron transfer reagents have been described. Kang et al. reported the decyanation of both malononitriles and $\alpha$-cyanoesters using samarium(II) iodide/THF/HMPA at respectively $0{ }^{\circ} \mathrm{C}$ and room temperature [123]. Metallic samarium can also promote the decyanation [124].

Doni and Murphy have reported the reductive decyanation of malononitriles and $\alpha$-cyanoesters by using the neutral organic electron donor 78 (Scheme 25) under photoactivation (method A, Scheme 26) [125]. The first observation was that surprisingly, the reaction of 2,2-dibenzylmalononitrile (72b) provided<smiles>[R]C([R])([R])C#N</smiles><smiles>[R]C([R2])C([R])C#N</smiles>

$73 \quad 74 n=1(66-91 \%)$ $75 n=2($ trace $-12 \%)$<smiles>COCC(C#N)CCc1ccccc1</smiles>

73e, $74 \%$

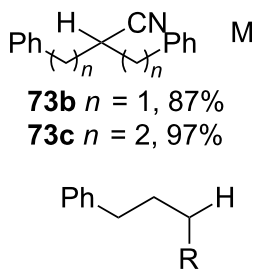

73f $\mathrm{R}=\mathrm{CN}, 96 \%$ 73g R $=\mathrm{CO}_{2} \mathrm{Me}, 72 \%$<smiles></smiles>

73d, $94 \%$<smiles>[R]c1ccc(CCC#N)cc1</smiles>

73h $\mathrm{R}=\mathrm{Cl}, 93 \%$ 73i $\mathrm{R}=\mathrm{Br}, 80 \%$ 
<smiles></smiles><smiles></smiles>

Scheme 24: Proposed mechanism for the reduction by NHC-boryl radicals. The other possible pathway (addition of $\mathbf{7 6}$ to the nitrogen) is not represented here [121].

both debenzylated (2-benzylmalononitrile, 19\%) and decyanation $(\mathbf{7 3 b}, 75 \%)$ products. In contrast, the corresponding dibenzylcyanoacetate led exclusively to the debenzylation product [126]. Selected examples are presented in Scheme 26. Excellent yields are obtained even if decyanation of cyanoacetates requires higher amounts of $\mathbf{7 8}$ (6 equiv) with extended reaction times $(72 \mathrm{~h})$. In line with this work, the authors prepared the tetra(iminophosphorano)-substituted bispyridinylidene 80, a new highly efficient neutral organic electron donor (Scheme 25) [127]. This compound is able to reduce aryl halides and appears as the only reductant able to reduce dialkylarenesulfonamides as well as malononitriles without photoexcitation. Electron donor $\mathbf{8 0}$ can be isolated but is more conveniently generated in situ by deprotonation with KHMDS of its pyridinium ion precursor $\mathbf{7 9}$ in refluxing toluene (method B).

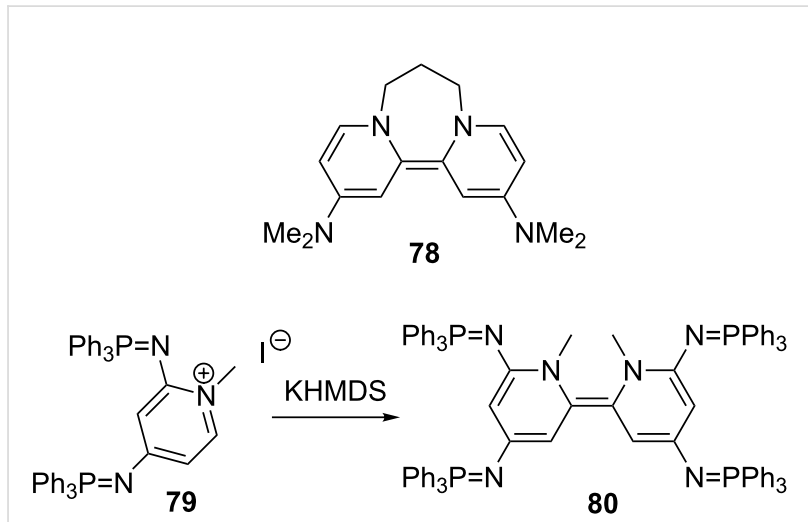

Scheme 25: Structures of organic electron-donors. Only the major $Z$ isomer of $\mathbf{8 0}$ is shown $[125,127]$.

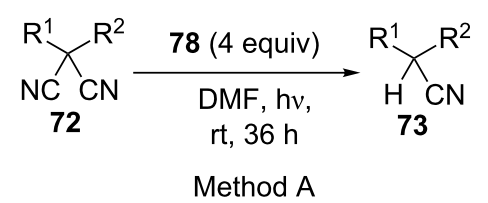

$$
{ }_{\mathrm{H}}^{\mathrm{R}}>_{\mathrm{CN}}^{\mathrm{R}}
$$

73b $\mathrm{R}=\mathrm{Bn}, 75 \%(6$ equiv $78,72 \mathrm{~h})$ 73j $\mathrm{R}=n-\mathrm{C}_{11} \mathrm{H}_{23}, 92 \%$<smiles>CC(C)=CCC(C#N)CC=C(C)C</smiles>

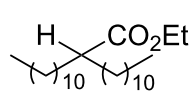<smiles>CC(C#N)CNc1ccccc1</smiles>

73k, 92\%, 24 h, (92\%)

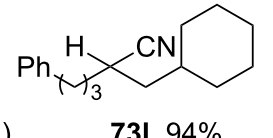<smiles>C=CCC(C)C(C)CC=C</smiles>

73m, 91\% (91\%)

73n, 90\% (89\%)

73o, $91 \%$ ( 6 equiv $78,72 h)$<smiles>CCOC(=O)C(C)C(C)(N)c1ccccc1</smiles>

$73 p, 94 \%$ ( 6 equiv 78,72 h)

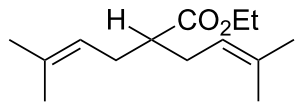

$\mathbf{7 3 q}, 88 \%$ ( 6 equiv $\mathbf{7 8}, 72 \mathrm{~h}$ ) 
With method B, malononitriles are reduced to mononitriles with comparable yields to that achieved with photoactivated $\mathbf{7 8}$ $(\mathbf{7 3 k}, \mathbf{m}, \mathbf{n})$. No allylic bond cleavage is observed and alkene moieties are preserved in the decyanated product $(\mathbf{7 3 m}, \mathbf{n}, \mathbf{q})$. No radicals are trapped from the reduction of the 5-hexenyl radical probe $\mathbf{7 2 m}$ with both methods. Mononitrile 2,2-dimethylhexadecanenitrile appears inert with both methods, and organic bromides are not tolerated. The proposed mechanism is similar to Scheme 1. First, a SET from the electron donor to the nitrile forms a radical anion. This radical anion can fragment into a cyanide ion and a radical which is rapidly reduced into a stabilized carbanion before protonation. This carbanion appears as a key intermediate leading to complex mixtures when method A is applied to $\mathbf{7 2 d}$ or a substrate similar to $\mathbf{7 2 e}$.

More recently, the reaction of dibenzylmalononitrile $\mathbf{7 2 b}$ with the hydroxyaryl-substituted benzimidazoline derivative $\mathbf{8 1}$ as photo-reductant in a basic medium has been described and led to 73b in fair yield (Scheme 27) [128].

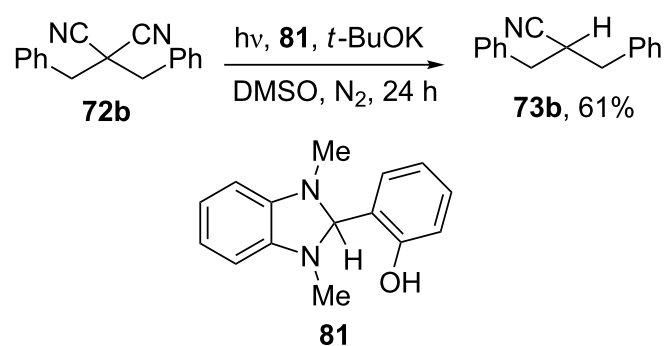

Scheme 27: Photoreaction of dibenzylmalononitrile with 81 [128].

\section{Acid, base or organometallic-induced reduc- tive decyanation}

Among the other procedures mentioned in our previous review [9], the base $[129,130]$ or acid-induced [131-134] hydro- lysis-decarboxylation sequence appears as a classical pathway (Scheme 28).

In the particular case of diphenylacetonitriles, an addition-elimination mechanism is proposed (Scheme 29) [135,136]. Such a pathway could also apply for the reductive decyanation of diphenylacetonitriles induced by organolithiums or Grignard reagents $[137,138]$. This reaction, applied to nitriles substituted with suitable leaving groups appears as a cyanation method of organometallic reagents or other nucleophiles [139].

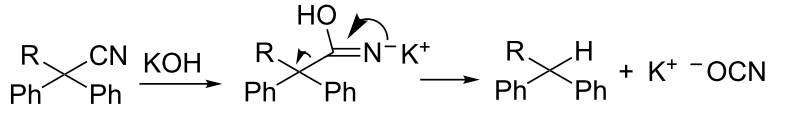

Scheme 29: Mechanism proposed for the base-induced reductive decyanation of diphenylacetonitriles [136].

Nambo et al described the preparation of triarylacetonitriles using sequential Pd-catalyzed arylations. Triarylacetonitriles obtained can be transformed into various species including triarylmethanes by treatment with $\mathrm{MeMgCl}$ (Scheme 30) [140]. In this case a SET mechanism could operate [141].

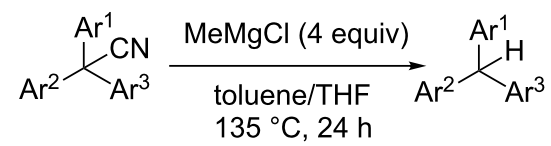

$\mathrm{Ar}^{1}=\mathrm{Ar}^{2}=\mathrm{Ar}^{3}=\mathrm{Ph}, 94 \%$

$\mathrm{Ar}^{1}=\mathrm{Ph}, \mathrm{Ar}^{2}=p-\mathrm{MeC}_{6} \mathrm{H}_{4}, \mathrm{Ar}^{3}=p-\mathrm{MeOC}_{6} \mathrm{H}_{4}, 93 \%$

Scheme 30: Reductive decyanation of triarylacetonitriles [140].<smiles>COc1cc2c(c(-c3ccccc3)nn2-c2ccccc2)c2c1CCCC2</smiles><smiles>Cc1c(C#N)c(N)c2c(ccc3ccccc32)c1C</smiles>

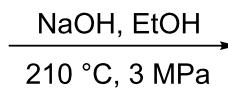<smiles>Cc1cc(N)c2c(ccc3ccccc32)c1C</smiles>

$92 \%$

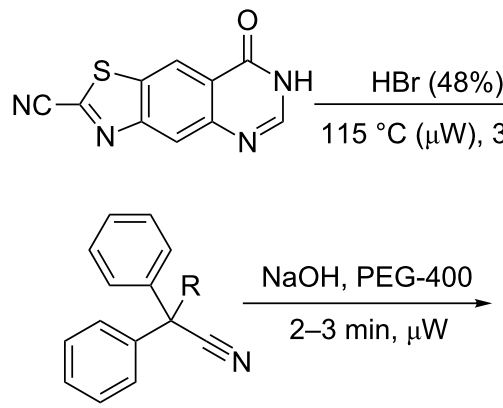

$\mathrm{R}=\mathrm{H}, 98 \%$

$\mathrm{R}=\mathrm{Et}, 93 \%$

$\mathrm{R}=\left(\mathrm{CH}_{2}\right)_{3} \mathrm{OH}, 86 \%$

$\mathrm{R}=\mathrm{CH}_{2} \mathrm{CO}_{2} \mathrm{H}, 89 \%$ 


\section{Conclusion}

The reductive decyanation reaction appears useful in organic synthesis because it offers the possibility to temporarily use the advantages from the nitrile functional group. While our previous review showed that several methods had a narrow substrate scope [9], new and convenient synthetic methods have now emerged. Classical metal dissolving conditions are still used but the method, while it works, shows that the course of the reaction may strongly depend on reaction conditions. The transition-metal-catalyzed defunctionalization reactions cover a wide range of nitriles including the most challenging alkanenitriles and allow a large functional group tolerance. The decyanation of $\alpha$-aminonitriles by aluminium- and borohydrides has been widely investigated and offers synthetic applications in heterocyclic chemistry. Recent developments using $\mathrm{N}$-heterocyclic carbene boranes and super electron donors provide new procedures for the reduction of malononitriles or $\alpha$-cyanoesters. This opens the possibility to synthetic applications by using these intermediates in the future.

\section{References}

1. Zhao, L.; Wen, M.; Wang, Z.-X. Eur. J. Org. Chem. 2012, 3587-3597. doi:10.1002/ejoc.201200121

2. Huang, Q.; Tran, G.; Pardo, D. G.; Tsuchiya, T.; Hillebrand, S.; Vors, J.-P.; Cossy, J. Tetrahedron 2015, 71, 7250-7259. doi:10.1016/j.tet.2015.03.099

3. Reddy, M. C.; Jeganmohan, M. Chem. Commun. 2015, 51, 10738-10741. doi:10.1039/c5cc03112e

4. Bera, M.; Modak, A.; Patra, T.; Maji, A.; Maiti, D. Org. Lett. 2014, 16, 5760-5763. doi:10.1021/ol502823c

5. Bera, M.; Maji, A.; Sahoo, S. K.; Maiti, D. Angew. Chem., Int. Ed. 2015, 54, 8515-8519. doi:10.1002/anie.201503112

6. Du, B.; Jiang, X.; Sun, P. J. Org. Chem. 2013, 78, 2786-2791. doi:10.1021/jo302765g

7. López, R.; Palomo, C. Angew. Chem., Int. Ed. 2015, 54, 13170-13184. doi:10.1002/anie.201502493

8. Fleming, F. F.; Zhang, Z. Tetrahedron 2005, 61, 747-789. doi:10.1016/j.tet.2004.11.012

9. Mattalia, J.-M.; Marchi-Delapierre, C.; Hazimeh, H.; Chanon, M. ARKIVOC 2006, iv, 90-118. doi:10.3998/ark.5550190.0007.408

10. Arapakos, P. G. J. Am. Chem. Soc. 1967, 89, 6794-6796. doi:10.1021/ja01001a090

11. Rychnovsky, S. D.; Rogers, B. N.; Richardson, T. I. Acc. Chem. Res. 1998, 31, 9-17. doi:10.1021/ar960223n

12. Schleicher, K. D.; Jamison, T. F. Beilstein J. Org. Chem. 2013, 9, 1533-1550. doi:10.3762/bjoc.9.175

13. McLachlan, M. M. W.; O'Connor, P. D.; Fairweather, K. A.; Willis, A. C.; Mander, L. N. Aust. J. Chem. 2010, 63, 742-760. doi:10.1071/CH10056

14. Sinz, C. J.; Rychnovsky, S. D. Top. Curr. Chem. 2001, 216, 51-92. doi:10.1007/3-540-44726-1_2

15. Rychnovsky, S. D. Chem. Rev. 1995, 95, 2021-2040. doi:10.1021/cr00038a011

16. Arapakos, P. G.; Scott, M. K.; Huber, F. E., Jr. J. Am. Chem. Soc. 1969, 91, 2059-2062. doi:10.1021/ja01036a033
17. Larchevêque, M.; Cuvigny, T. Tetrahedron Lett. 1975, 16, 3851-3854. doi:10.1016/S0040-4039(00)91294-2

18. Rojas, G.; Wagener, K. B. J. Org. Chem. 2008, 73, 4962-4970. doi:10.1021/jo800640j

19. Ohsawa, T.; Kobayashi, T.; Mizuguchi, Y.; Saitoh, T.; Oishi, T. Tetrahedron Lett. 1985, 26, 6103-6106. doi:10.1016/S0040-4039(00)95137-2

20. Baek, D. J.; Bittman, R. Chem. Phys. Lipids 2013, 175-176, 99-104. doi:10.1016/j.chemphyslip.2013.08.003

21. Amancha, P. K.; Lai, Y.-C.; Chen, I.-C.; Liu, H.-J.; Zhu, J.-L. Tetrahedron 2010, 66, 871-877. doi:10.1016/j.tet.2009.11.105

22. Amancha, P. K.; Liu, H.-J.; Ly, T. W.; Shia, K.-S. Eur. J. Org. Chem. 2010, 3473-3480. doi:10.1002/ejoc.201000318

23. Perry, M. A.; Rychnovsky, S. D. Nat. Prod. Rep. 2015, 32, 517-533. doi:10.1039/c4np00125g

24. Zeller, E.; Sajus, H.; Grierson, D. S. Synlett 1991, 44-46. doi:10.1055/s-1991-20623

25. La Cruz, T. E.; Rychnovsky, S. D. Org. Lett. 2005, 7, 1873-1875. doi:10.1021/ol050589c

26. Tsao, J.-P.; Tsai, T.-Y.; Chen, I.-C.; Liu, H.-J.; Zhu, J.-L.; Tsao, S.-W. Synthesis 2010, 4242-4250. doi:10.1055/s-0030-1258301

27. Cacciarini, M.; Jevric, M.; Elm, J.; Petersen, A. U.; Mikkelsen, K. V.; Nielsen, M. B. RSC Adv. 2016, 6, 49003-49010. doi:10.1039/c6ra06045e

28. Yus, M.; Foubelo, F. Dissolving Metals. In Modern Reduction Methods; Andersson, P. G.; Munslow, I. J., Eds.; Wiley-VCH: Weinheim, Germany, 2008; pp 419-445. doi:10.1002/9783527622115.ch17

29. Mander, L. N.; McLachlan, M. M. J. Am. Chem. Soc. 2003, 125 , 2400-2401. doi:10.1021/ja029725o

30. Richardson, T. I.; Rychnovsky, S. D. Tetrahedron 1999, 55, 8977-8996. doi:10.1016/s0040-4020(99)00457-3

31. Sinz, C. J.; Rychnovsky, S. D. Angew. Chem., Int. Ed. 2001, 40, 3224-3227. doi:10.1002/1521-3773(20010903)40:17<3224::aid-anie3224>3.0.co; 2-d

32. da Silva, L. C.; Wagener, K. B. Macromol. Chem. Phys. 2016, 217, 850-855. doi:10.1002/macp.201500508

33. Rojas, G.; Baughman, T. W.; Wagener, K. B. Synth. Commun. 2007, 37, 3923-3931. doi:10.1080/00397910701572456

34. Savoia, D.; Tagliavini, E.; Trombini, C.; Umani-Ronchi, A. J. Org. Chem. 1980, 45, 3227-3229. doi:10.1021/jo01304a016

35. Bailey, W. F.; Punzalan, E. R. J. Am. Chem. Soc. 1994, 116, 6577-6580. doi:10.1021/ja00094a012

36. Sánchez-Sánchez, C.; Pérez-Inestrosa, E.; García-Segura, R.; Suau, R. Tetrahedron 2002, 58, 7267-7274. doi:10.1016/s0040-4020(02)00756-1

37. Mertens, R.; von Sonntag, C. J. Photochem. Photobiol., A: Chem 1995, 85, 1-9. doi:10.1016/1010-6030(94)03903-8

38. Ashworth, B.; Gilbert, B. C.; Norman, R. O. C. J. Chem. Res., Synop. 1977, 94-95.

39. Luján-Montelongo, J. A.; Covarrubias-Zúñiga, A.; Romero-Ortega, M.; Avila-Zárraga, J. G. Lett. Org. Chem. 2008, 5, 470-472. doi:10.2174/157017808785740525

40. Maercker, A. Angew. Chem., Int. Ed. Engl. 1987, 26, 972-989. doi:10.1002/anie.198709721

41. Lahm, G.; Orejarena Pacheco, J. C.; Opatz, T. Synthesis 2014, 46, 2413-2421. doi:10.1055/s-0034-1378393

42. Opatz, T. Synthesis 2009, 1941-1959. doi:10.1055/s-0029-1216839 
43. Otto, N.; Opatz, T. Chem. - Eur. J. 2014, 20, 13064-13077. doi:10.1002/chem.201403956

44. Husson, H.-P.; Royer, J. Chem. Soc. Rev. 1999, 28, 383-394. doi:10.1039/a900153k

45. Girard, N.; Pouchain, L.; Hurvois, J.-P.; Moinet, C. Synlett 2006, 1679-1682. doi:10.1055/s-2006-944214

46. Louafi, F.; Hurvois, J.-P.; Chibani, A.; Roisnel, T. J. Org. Chem. 2010, 75, 5721-5724. doi:10.1021/jo100714y

47. Orejarena Pacheco, J. C.; Lahm, G.; Opatz, T. J. Org. Chem. 2013, 78, 4985-4992. doi:10.1021/jo400659n

48. Shahane, S.; Louafi, F.; Moreau, J.; Hurvois, J.-P.; Renaud, J.-L.; van de Weghe, P.; Roisnel, T. Eur. J. Org. Chem. 2008, 4622-4631. doi:10.1002/ejoc.200800512

49. Vu, V. H.; Louafi, F.; Girard, N.; Marion, R.; Roisnel, T.; Dorcet, V.; Hurvois, J.-P. J. Org. Chem. 2014, 79, 3358-3373. doi:10.1021/j0500104c

50. Louafi, F.; Moreau, J.; Shahane, S.; Golhen, S.; Roisnel, T.; Sinbandhit, S.; Hurvois, J.-P. J. Org. Chem. 2011, 76, 9720-9732. doi:10.1021/jo2017982

51. Benmekhbi, L.; Louafi, F.; Roisnel, T.; Hurvois, J.-P. J. Org. Chem. 2016, 81, 6721-6739. doi:10.1021/acs.joc.6b01419

52. Amat, M.; Gómez-Esqué, A.; Escolano, C.; Santos, M. M. M.; Molins, E.; Bosch, J. J. Org. Chem. 2009, 74, 1205-1211. doi:10.1021/j0802387c

53. Lahm, G.; Stoye, A.; Opatz, T. J. Org. Chem. 2012, 77, 6620-6623. doi:10.1021/jo3011045

54. Bergner, I.; Wiebe, C.; Meyer, N.; Opatz, T. J. Org. Chem. 2009, 74, 8243-8253. doi:10.1021/jo901759u

55. Bergner, I.; Opatz, T. Synthesis 2007, 918-928. doi:10.1055/s-2007-965937

56. Maloney, K. M.; Danheiser, R. L. Org. Lett. 2005, 7, 3115-3118. doi:10.1021/ol051185n

57. Meyer, N.; Opatz, T. Synlett 2003, 1427-1430. doi:10.1055/s-2003-40842

58. Meyer, N.; Opatz, T. Synlett 2004, 787-790. doi:10.1055/s-2004-817774

59. Orejarena Pacheco, J. C.; Lipp, A.; Nauth, A. M.; Acke, F.; Dietz, J.-P.; Opatz, T. Chem. - Eur. J. 2016, 22, 5409-5415. doi:10.1002/chem.201504845

60. Kison, C.; Opatz, T. Eur. J. Org. Chem. 2008, 2740-2745. doi:10.1002/ejoc.200701205

61. Ogura, K.; Shimamura, Y.; Fujita, M. J. Org. Chem. 1991, 56, 2920-2922. doi:10.1021/jo00008a062

62. Guerrier, L.; Royer, J.; Grierson, D. S.; Husson, H.-P. J. Am. Chem. Soc. 1983, 105, 7754-7755. doi:10.1021/ja00364a053

63. Royer, J.; Husson, H.-P. J. Org. Chem. 1985, 50, 670-673. doi:10.1021/jo00205a023

64. Grierson, D. S.; Royer, J.; Guerrier, L.; Husson, H.-P. J. Org. Chem. 1986, 51, 4475-4477. doi:10.1021/jo00373a027

65. Orejarena Pacheco, J. C.; Opatz, T. J. Org. Chem. 2014, 79, 5182-5192. doi:10.1021/jo500749x

66. Tankabekyan, N. A.; Mokhov, V. M.; Popov, Yu. V. Russ. J. Org. Chem. 2014, 50, 1056-1057. doi:10.1134/s1070428014070215

67. Yamada, S.; Tomioka, K.; Koga, K. Tetrahedron Lett. 1976, 17, 61-64. doi:10.1016/s0040-4039(00)71323-2

68. Zhu, J.; Quirion, J.-C.; Husson, H.-P. J. Org. Chem. 1993, 58, 6451-6456. doi:10.1021/jo00075a048

69. Meyer, N.; Werner, F.; Opatz, T. Synthesis 2005, 945-956. doi:10.1055/s-2005-861838
70. Badru, R.; Singh, B. RSC Adv. 2014, 4, 38978-38985. doi:10.1039/c4ra08048c

71. Chang, C.-F.; Li, C.-F.; Tsai, C.-C.; Chuang, T.-H. Org. Lett. 2016, 18, 638-641. doi:10.1021/acs.orglett.5b03395

72. Kison, C.; Opatz, T. Synthesis 2006, 3727-3738. doi:10.1055/s-2006-950237

73. Kison, C.; Meyer, N.; Opatz, T. Angew. Chem., Int. Ed. 2005, 44, 5662-5664. doi:10.1002/anie.200501705

74. Li, J.; Zhao, H.; Jiang, X.; Wang, X.; Hu, H.; Yu, L.; Zhang, Y. Angew. Chem., Int. Ed. 2015, 54, 6306-6310. doi:10.1002/anie.201500961

75. Li, J.; Zhao, H.; Zhang, Y. Synlett 2015, 2745-2750. doi:10.1055/s-0035-1560178

76. Black, D. S. C.; Doyle, J. E. Aust. J. Chem. 1978, 31, 2323-2326. doi:10.1071/ch9782323

77. Mattalia, J.-M.; Bodineau, N.; Negrel, J.-C.; Chanon, M. J. Phys. Org. Chem. 2000, 13, 233-236. doi:10.1002/1099-1395(200005)13:5<233::aid-poc235>3.0.co;2-o

78. Mattalia, J.-M.; Samat, A.; Chanon, M. J. Chem. Soc., Perkin Trans. 1 1991, 1769-1770. doi:10.1039/P19910001769

79. Németh, G.; Poszávácz, L.; Bózsing, D.; Simig, G. J. Fluorine Chem. 1996, 78, 87-89. doi:10.1016/0022-1139(96)03433-1

80. Cacciarini, M.; Skov, A. B.; Jevric, M.; Hansen, A. S.; Elm, J.; Kjaergaard, H. G.; Mikkelsen, K. V.; Nielsen, M. B. Chem. - Eur. J. 2015, 21, 7454-7461. doi:10.1002/chem.201500100

81. Too, P. C.; Chan, G. H.; Tnay, Y. L.; Hirao, H.; Chiba, S. Angew. Chem., Int. Ed. 2016, 55, 3719-3723. doi:10.1002/anie.201600305

82. Hong, Z.; Ong, D. Y.; Muduli, S. K.; Too, P. C.; Chan, G. H.; Tnay, Y. L.; Chiba, S.; Nishiyama, Y.; Hirao, H.; Soo, H. S. Chem. - Eur. J. 2016, 22, 7108-7114. doi:10.1002/chem.201600340

83. François, D.; Poupon, E.; Kunesch, N.; Husson, H.-P. Eur. J. Org. Chem. 2004, 4823-4829. doi:10.1002/ejoc.200400404

84. François, D.; Poupon, E.; Lallemand, M.-C.; Kunesch, N.; Husson, H.-P. J. Org. Chem. 2000, 65, 3209-3212. doi:10.1021/jo990706f

85. Mokhov, V. M.; Popov, Yu. V.; Shcherbakova, K. V. Russ. J. Gen. Chem. 2016, 86, 273-280. doi:10.1134/s1070363216020110

86. Weigert, F. J.; Moguel, M. J. Mol. Catal. 1992, 75, 209-218. doi:10.1016/0304-5102(92)80123-X

87. Liao, Z.; Lv, X.; Tao, M. Res. Chem. Intermed. 2013, 39, 4021-4024. doi:10.1007/s11164-012-0918-x

88. Uematsu, N.; Fujii, A.; Hashiguchi, S.; Ikariya, T.; Noyori, R. J. Am. Chem. Soc. 1996, 118, 4916-4917. doi:10.1021/ja960364k

89. Werner, F.; Blank, N.; Opatz, T. Eur. J. Org. Chem. 2007, 3911-3915. doi:10.1002/ejoc.200700261

90. Blank, N.; Opatz, T. J. Org. Chem. 2011, 76, 9777-9784. doi:10.1021/jo201871c

91. Geffe, M.; Opatz, T. Org. Lett. 2014, 16, 5282-5285. doi:10.1021/ol5023849

92. Ozawa, F.; Iri, K.; Yamamoto, A. Chem. Lett. 1982, 11, 1707-1710. doi:10.1246/cl.1982.1707

93. Chen, F.; Wang, T.; Jiao, N. Chem. Rev. 2014, 114, 8613-8661. doi:10.1021/cr400628s

94. Kita, Y.; Tobisu, M.; Chatani, N. J. Synth. Org. Chem., Jpn. 2010, 68, 1112-1122. doi:10.5059/yukigoseikyokaishi.68.1112

95. Modak, A.; Maiti, D. Org. Biomol. Chem. 2016, 14, 21-35. doi:10.1039/c5ob01949d 
96. Nakao, Y. Top. Curr. Chem. 2014, 346, 33-58. doi:10.1007/128_2013_494

97. Souillart, L.; Cramer, N. Chem. Rev. 2015, 115, 9410-9464. doi:10.1021/acs.chemrev.5b00138

98. Wen, Q.; Lu, P.; Wang, Y. RSC Adv. 2014, 4, 47806-47826. doi:10.1039/c4ra08675a

99. Wang, R.; Falck, J. R. Catal. Rev.: Sci. Eng. 2014, 56, 288-331. doi:10.1080/01614940.2014.920178

100. Nakazawa, H.; Itazaki, M.; Mamata, K.; Ueda, K. Chem. - Asian J. 2007, 2, 882-888. doi:10.1002/asia.200700076

101. Nakazawa, H.; Kamata, K.; Itazaki, M. Chem. Commun. 2005 , 4004-4006. doi:10.1039/b504131g

102.Tobisu, M.; Nakamura, R.; Kita, Y.; Chatani, N. J. Am. Chem. Soc. 2009, 131, 3174-3175. doi:10.1021/ja810142v

103. Tobisu, M.; Nakamura, R.; Kita, Y.; Chatani, N. Bull. Korean Chem. Soc. 2010, 31, 582-587. doi:10.5012/bkcs.2010.31.03.582

104.Patra, T.; Agasti, S.; Maiti, A.; Maiti, D. Chem. Commun. 2013, 49, 69-71. doi:10.1039/c2cc36883h

105.Patra, T.; Agasti, S.; Modak, A.; Maiti, D. Chem. Commun. 2013, 49 8362-8364. doi:10.1039/c3cc44562c

106.Weidauer, M.; Someya, C. I.; Irran, E.; Enthaler, S. Asian J. Org. Chem. 2013, 2, 150-156. doi:10.1002/ajoc.201200185

107.Enthaler, S.; Weidauer, M.; Irran, E.; Epping, J. D.; Kretschmer, R.; Someya, C. I. J. Organomet. Chem. 2013, 745-746, 262-274. doi:10.1016/j.jorganchem.2013.07.068

108.Someya, C. I.; Inoue, S.; Irran, E.; Enthaler, S. Inorg. Chem. Commun. 2014, 44, 114-118. doi:10.1016/j.inoche.2014.03.014

109.Dandia, A.; Singh, R.; Maheshwari, S. Curr. Org. Chem. 2014, 18, 2513-2529. doi:10.2174/138527281819141028114524

110.Diaz-de-Villegas, M. D.; Gálvez, J. A.; Badorrey, R.; López-Ram-de-Viu, P. Adv. Synth. Catal. 2014, 356, 3261-3288. doi:10.1002/adsc.201400404

111. Inokuma, T.; Hoashi, Y.; Takemoto, Y. J. Am. Chem. Soc. 2006, 128, 9413-9419. doi:10.1021/ja061364f

112.Pal, S.; Khan, M. N.; Karamthulla, S.; Choudhury, L. H. Tetrahedron Lett. 2015, 56, 359-364. doi:10.1016/j.tetlet.2014.11.095

113.Kang, S. R.; Lee, Y. R. Synthesis 2013, 45, 2593-2599. doi:10.1055/s-0033-1338506

114.Curran, D. P.; Seong, C. M. J. Am. Chem. Soc. 1990, 112, 9401-9403. doi:10.1021/ja00181a057

115.Curran, D. P.; Seong, C. M. Synlett 1991, 107-108. doi:10.1055/s-1991-20644

116.Deme, R.; Schlich, M.; Mucsi, Z.; Karvaly, G.; Tóth, G.; Mátyus, P. ARKIVOC 2016, v, 164-196. doi:10.3998/ark.5550190.p009.692

117.Gerlach, U. Tetrahedron Lett. 1995, 36, 5159-5162. doi:10.1016/0040-4039(95)01006-4

118. Hattori, K.; Grossman, R. B. J. Org. Chem. 2003, 68, 1409-1417. doi:10.1021/jo026643+

119.Tong, B. M. K.; Chen, H.; Chong, S. Y.; Heng, Y. L.; Chiba, S. Org. Lett. 2012, 14, 2826-2829. doi:10.1021/ol301044e

120.Tong, B. M. K.; Chen, H.; Chong, S. Y.; Heng, Y. L.; Chiba, S. Org. Lett. 2013, 15, 6111-6112. doi:10.1021/ol4032842

121. Kawamoto, T.; Geib, S. J.; Curran, D. P. J. Am. Chem. Soc. 2015, 137, 8617-8622. doi:10.1021/jacs.5b04677

122.Giles, J. R. M.; Roberts, B. P. J. Chem. Soc., Perkin Trans. 2 1983, 743-755. doi:10.1039/P29830000743

123.Kang, H.-Y.; Hong, W. S.; Cho, Y. S.; Koh, H. Y. Tetrahedron Lett. 1995, 36, 7661-7664. doi:10.1016/0040-4039(95)01606-i
124.Liu, Y.; Zhang, F.; Qi, Y.; Zhang, Y.; Zhang, S. Eur. J. Org. Chem. 2008, 5470-5476. doi:10.1002/ejoc.200800258

125.Doni, E.; Murphy, J. A. Org. Chem. Front. 2014, 1, 1072-1076. doi:10.1039/c4qo00202d

126. Doni, E.; Mondal, B.; O'Sullivan, S.; Tuttle, T.; Murphy, J. A. J. Am. Chem. Soc. 2013, 135, 10934-10937. doi:10.1021/ja4050168

127. Hanson, S. S.; Doni, E.; Traboulsee, K. T.; Coulthard, G.; Murphy, J. A.; Dyker, C. A. Angew. Chem., Int. Ed. 2015, 54, 11236-11239. doi:10.1002/anie.201505378

128. Hasegawa, E.; Izumiya, N.; Fukuda, T.; Nemoto, K.; Iwamoto, H.; Takizawa, S.-y.; Murata, S. Tetrahedron 2016, 72, 7805-7812. doi:10.1016/j.tet.2016.05.078

129. Krasodomski, W.; Łuczyński, M. K.; Wilamowski, J.; Sepioł, J. J. Tetrahedron 2003, 59, 5677-5683. doi:10.1016/S0040-4020(03)00884-6

130. Yalçin, E.; Kutlu, Y. C.; Korkmaz, V.; Şahin, E.; Seferoğlu, Z. ARKIVOC 2015, v, 202-218. doi:10.3998/ark.5550190.p009.102

131.Hédou, D.; Guillon, R.; Lecointe, C.; Logé, C.; Chosson, E.; Besson, T. Tetrahedron 2013, 69, 3182-3191. doi:10.1016/j.tet.2013.02.066

132. Nandi, S.; Panda, K.; Suresh, J. R.; Ila, H.; Junjappa, H. Tetrahedron 2004, 60, 3663-3673. doi:10.1016/j.tet.2004.02.053

133.Panda, K.; Suresh, J. R.; Ila, H.; Junjappa, H. J. Org. Chem. 2003, 68 , 3498-3506. doi:10.1021/jo026786w

134.Peruncheralathan, S.; Khan, T. A.; Ila, H.; Junjappa, H. Tetrahedron 2004, 60, 3457-3464. doi:10.1016/j.tet.2004.02.029

135. Bendale, P. M.; Chowdhury, B. R.; Khadilkar, B. M. Indian J. Chem. 2001, 40B, 433-435.

136. Berkoff, C. E.; Rivard, D. E.; Kirkpatrick, D.; Ives, J. L. Synth. Commun. 1980, 10, 939-945. doi: $10.1080 / 00397918008061855$

137.Blicke, F. F.; Tsao, E.-P. J. Am. Chem. Soc. 1953, 75, 5587-5590. doi:10.1021/ja01118a032

138. Kulp, S. S.; Romanelli, A. Org. Prep. Proced. Int. 1992, 24, 7-12. doi:10.1080/00304949209356689

139. Reeves, J. T.; Malapit, C. A.; Buono, F. G.; Sidhu, K. P.; Marsini, M. A.; Sader, C. A.; Fandrick, K. R.; Busacca, C. A.; Senanayake, C. H. J. Am. Chem. Soc. 2015, 137, 9481-9488. doi:10.1021/jacs.5b06136

140.Nambo, M.; Yar, M.; Smith, J. D.; Crudden, C. M. Org. Lett. 2015, 17, 50-53. doi:10.1021/ol503213z

141.Polivin, Y. N.; Karakhanov, R. A.; Sheveleva, T. S.; Ageev, E. A.; Remizov, A. S. Izv. Akad. Nauk SSSR, Ser. Khim. 1991, 2886-2889. 


\section{License and Terms}

This is an Open Access article under the terms of the Creative Commons Attribution License

(http://creativecommons.org/licenses/by/4.0), which permits unrestricted use, distribution, and reproduction in any medium, provided the original work is properly cited.

The license is subject to the Beilstein Journal of Organic Chemistry terms and conditions:

(http://www.beilstein-journals.org/bjoc)

The definitive version of this article is the electronic one which can be found at:

doi:10.3762/bjoc. 13.30 